\title{
Three-Dimensional Stress-Strain State of a Pipe with Corrosion Damage Under Complex Loading
}

\author{
S. Sherbakov \\ Department of Theoretical and Applied Mechanics, Belarusian State University \\ Belarus
}

\section{Introduction}

In studies of the stress-stain state of models of pipeline sections without corrosion defects of a pipe, in the two-dimensional statement (cross section), pipes are usually modeled by a ring, whereas in the three-dimensional statement - by a thick-wall cylindrical shell [Ponomarev et al., 1958; Seleznev et al. 2005]. Usually, internal pressure or temperature is considered as a load applied to the pipe. The solution of the problems stated in this manner yields not bad results when a relatively not complicated procedure of calculation, both analytical and numerical, is adopted.

The presence of corrosion damage at the inner surface of the pipe (Figures 1, 2), being a particular three-dimensional concentrator of stresses, requires a special approach to defening the stress-strain state. In addition, account should be taken of a simultaneous compound action of such loading factors as internal pressure and friction of the mineral oil flow over the inner surface of the pipe, as well as of soil.

The analysis of the known references to articles shows that the problem of investigating the spatial stress-strain states of the pipe with regard to its corrosion damage with the account of various types of loading has not been stated up to now. In essence, the problems of determining individual stress-strain states under the action of internal pressure $\left(\sigma_{i j}^{(p)}, \varepsilon_{i j}^{(p)}\right)$ or temperature $\left(\sigma_{i j}^{(T)}, \varepsilon_{i j}^{(T)}\right)$ [Ainbinder et al., 1982; Borodavkin et al., 1984; Grachev et al., 1982; Dertsakyan et al., 1977; Mirkin et al., 1991; O'Grady et al., 1992] are under consideration. The problem of determining stress-strain state caused by wall friction due to viscous fluid motion $\left(\sigma_{i j}^{(\tau)}, \varepsilon_{i j}^{(\tau)}\right)$, as well as the most general problems of determining $\sigma_{i j}^{(p+\tau)}, \varepsilon_{i j}^{(p+\tau)} ; \sigma_{i j}^{(p+T)}, \varepsilon_{i j}^{(p+T)} ; \sigma_{i j}^{(p+\tau+T)} \varepsilon_{i j}^{(p+\tau+T)}$ has not been stated. In addition, the problems of stress-strain state determination are usually being solved for shell models of a pipe. Although, for example, in [Seleznev et al. 2005] $\sigma_{i j}^{(p)}$ is described for the threedimensional model of the section of the pipe with corrosion damage.

Therefore the statement and solutions of the problem of determining three-dimensional stress-strain state of the models of pipes with corrosion defects under the action of internal pressure, friction caused by oil flow and temperature discussed in the present chapter are 
important for pipeline systems and such related disciplines as solid mechanics, fluid mechanics and tribology.

\section{Statement of the problem}

The present Chapter deals with some of the results of investigation of the three-dimensional stress-strain state of the model of a pipe with corrosion damage (Figure 2).

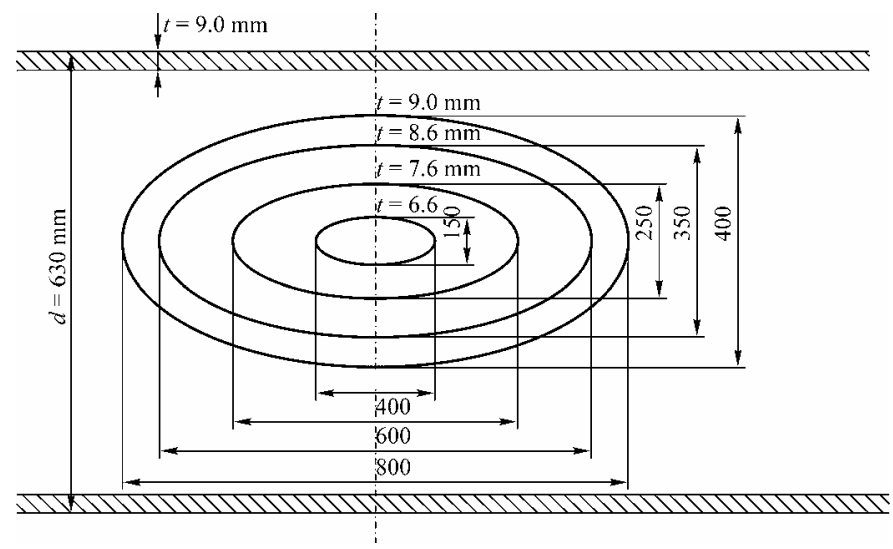

Fig. 1. Simplified scheme of elliptical corrosion damage at the inner surface of the pipe displaying reduced wall thickness inside the damage

In calculations, the following basic loads applied to the pipe were taken into consideration:

- internal pressure

$$
\left.\sigma_{r}\right|_{r=r_{1}}=p,
$$

where $r_{1}$ is the inner radius of the pipe;

- mineral oil friction over the inner surface of the pipe, thus exciting wall tangential stresses

$$
\left.\tau_{r z}\right|_{r=r_{1}}=\tau_{0}
$$

$\tau_{0}$ - tangential forces modeling the viscous fluid friction force over the inner surface of the pipe;

- change of the thermodynamic state (temperature) of the pipe

$$
\left|T_{r_{1}}-T_{r_{2}}\right|=\Delta T
$$

where $r_{2}$ is the outer radius of the pipe.

It should be emphasized that in the presence of corrosion damage

$$
r_{1}=r_{1}(\varphi, z),
$$

where $\varphi$ and $z$ are the components of the cylindrical coordinate system $(r, \varphi, z)$. 


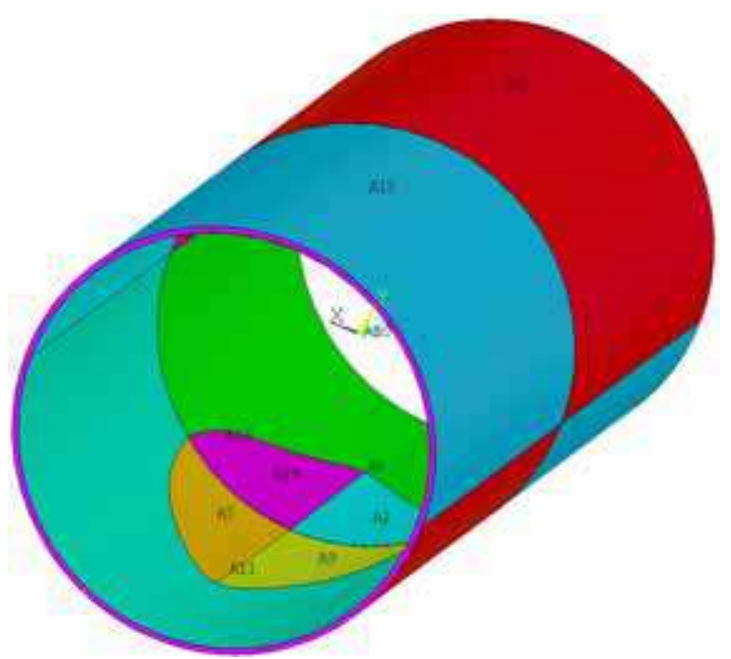

Fig. 2. Solid model of the neighborhood of the pipe with corrosion damage

The distinctive feature of computer finite-element modeling of pipes of trunk pipelines with corrosion damage lies in the opportunity to assign different boundary conditions for the outer surface of the pipe. So, for loads (1)-(3), consideration is made of different restrictions on displacements of the outer surface of the pipe:

a. no pipeline fixing

$$
\left.\sigma_{r}\right|_{r=r_{2}}=0,
$$

b. no displacements of the outer surface of the pipe in the $x$ and $y$ directions and in the $z$ direction on the right end

$$
\left.u_{x}\right|_{r=r_{2}}=\left.u_{y}\right|_{r=r_{2}}=0,\left.u_{z}\right|_{z=L}=0 \text {, }
$$

c. no displacements of the outer surface of the pipe in all directions

$$
\left.u_{x}\right|_{r=r_{2}}=\left.u_{y}\right|_{r=r_{2}}=\left.u_{z}\right|_{r=r_{2}}=0 \text {, }
$$

d. contact between the pipe and soil where no displacements of the soil outer surface take place

$$
\begin{aligned}
& \left.\sigma_{r}^{(1)}\right|_{r=r_{2}}=-\left.\sigma_{r}^{(2)}\right|_{r=r_{2}}, \\
& \left.\sigma_{\tau}^{(1)}\right|_{r=r_{2}}=-\left.\sigma_{\tau}^{(2)}\right|_{r=r_{2}}=\left.f \sigma_{n}^{(1)}\right|_{r=r_{2}}, \\
& \left.u_{x}\right|_{r=r_{3}}=\left.u_{y}\right|_{r=r_{3}}=0
\end{aligned}
$$

where the superscript 1 means the pipe, whereas 2 - soil, $\sigma_{\tau}$ is the tangential component of the stress vector, $f$ is the friction coefficient, and $r_{3}$ is the soil outer radius. 
With the use of the pipeline fixing (type a), tests of the pipe dug out of soil (in the air) are modeled. The stress-strain state of a pipe lying in hard soil without friction in the axial direction is modeled by means of pipe fixing (type b) while that of a pipe lying in hard soil and rigidly connected with it - by means of pipe fixing (type c). Subject to boundary conditions (8) (type d), a pipe lying in soil having particular mechanical characteristics is modeled.

Thus, the problem has been stated to make a comparative analysis of the stress-strain states of the pipe with corrosion damage for different combinations of boundary conditions (1)(3), (6)-(8):

$$
\begin{gathered}
\sigma_{i j}^{(p)}, \varepsilon_{i j}^{(p)} ; \sigma_{i j}^{(\tau)}, \varepsilon_{i j}^{(\tau)} ; \sigma_{i j}^{(T)}, \varepsilon_{i j}^{(T)} ; \\
\sigma_{i j}^{(p+\tau)}, \varepsilon_{i j}^{(p+\tau)} ; \sigma_{i j}^{(p+T)}, \varepsilon_{i j}^{(p+T)} ; \sigma_{i j}^{(p+\tau+T)}, \varepsilon_{i j}^{(p+\tau+T)} .
\end{gathered}
$$

where the superscripts $p, \tau$, and $T$ correspond to the stress states caused by internal pressure, friction force over the inner surface of the pipe, and temperature.

In the case of the elastic relationship between stresses and strains, the stress states in (9) are connected by the following relations

$$
\begin{aligned}
& \sigma_{i j}^{(p+\tau)}=\sigma_{i j}^{(p)}+\sigma_{i j}^{(\tau)}, \\
& \sigma_{i j}^{(p+T)}=\sigma_{i j}^{(p)}+\sigma_{i j}^{(T)}, \\
& \sigma_{i j}^{(p+\tau+T)}=\sigma_{i j}^{(p)}+\sigma_{i j}^{(\tau)}+\sigma_{i j}^{(T)} .
\end{aligned}
$$

Further, some of the solutions to more than 70 problems of studying the stress-strain state of the pipe cross section in the damage area (dot-and-dash line in Figure 1) [Kostyuchenko et al., 2007a; 2007b; Sherbakov et al., 2007b; 2008a; 2008b; Sherbakov, 2007b; Sosnovskiy et al., 2008] are analyzed. These two-dimensional problems mainly describe the stress-strain states of straight pipes with different-profile damage along the axis. Also, with the use of the finite-element method implemented in the software ANSYS, the essentially threedimensional stress-strain state of the pipe in the three-dimensional damage area (Figure 1) was investigated.

\section{Wall friction in the turbulent mineral oil flow in the pipe with corrosion damage}

Within the framework of the present work, hydrodynamic calculation was made of the motion characteristics of a viscous, incompressible, steady, isothermal fluid in a cylindrical channel that models a pipe and in a cylindrical channel with geometric characteristics with regard to the peculiarities of a pipe with corrosion damage (see, Sect. 2). Calculations were performed for the initial incoming flow velocities $v_{0}: 1 \mathrm{~m} / \mathrm{sec}$ and $10 \mathrm{~m} / \mathrm{sec}$.

The kinematic viscosity of fluid was taken equal to $v_{K}=1.410^{-4} \mathrm{~m}^{2} / \mathrm{sec}$, the viscous fluid density $-865 \mathrm{~kg} / \mathrm{m}^{3}$. The calculated Reynolds numbers will be, respectively,

$$
\operatorname{Re}_{1 \mathrm{~m} / \mathrm{sec}}=\frac{v_{0} D}{v_{K}}=\frac{1 \mathrm{~m} / \mathrm{sec}^{*} 0.612 \mathrm{~m}}{1.4^{*} 10^{-4} \mathrm{~m}^{2} / \mathrm{sec}}=4371.43,
$$




$$
\operatorname{Re}_{10 \mathrm{~m} / \mathrm{sec}}=\frac{v_{0} D}{v_{K}}=\frac{10 \mathrm{~m} / \mathrm{sec}^{*} 0.612 \mathrm{~m}}{1.4 * 10^{-4} \mathrm{~m}^{2} / \mathrm{sec}}=43714.3 .
$$

The critical Reynolds number (a transition from a laminar to a turbulent flow) for a viscous fluid moving in a round pipe is $\operatorname{Re}_{c r} \approx 2300$. Thus, the turbulent flow motion should be considered in our problem. The software Fluent calculations used the turbulence $k-\varepsilon$ model for modeling turbulent flow viscosity [Launder et al., 1972; Rodi, 1976].

As boundary conditions the following parameters were used: at the incoming flow surface the initial turbulence level equal to $7 \%$ was assigned; at the pipe walls the fixing conditions and the logarithmic velocity profile were predetermined; in the pipe the fluid pressure equal to $4 \mathrm{MPa}$ was set.

Calculations of the steady regime of the fluid flow (quasi-parabolic turbulent velocity profile of the incoming flow) and of the unsteady regime (rectangular velocity profile of the incoming flow) were made.

In the problems with a rectangular velocity profile of the incoming flow

$$
\left.v_{x}\right|_{x=0}=v_{r 1},
$$

The unsteady regime of the fluid flow was considered.

In the problems with a quasi-parabolic turbulent velocity profile, at the entrance surface of the pipe the empirically found profile of the initial velocity was assigned, which is determined by the formula:

- for the two-dimensional case

$$
\left.v_{x}\right|_{x=0}=v_{\max }\left(1-\frac{\left|r-2 r_{0}\right|}{2 r_{0}}\right)^{\frac{1}{7}}, v_{\max }=1.1428 v_{0}, 0 \leq r \leq 2 r_{1},
$$

- for the three-dimensional case

$$
\left.v_{x}\right|_{x=0}=v_{\max }\left(1-\frac{r}{r_{0}}\right)^{\frac{1}{7}}, v_{\max }=1.2244 v_{0}, r=\sqrt{y^{2}+z^{2}}, 0 \leq r \leq r_{1} .
$$

The calculation results have shown that the motion becomes steady (as the flow moves in the pipe, the quasi-parabolic turbulent profile of the longitudinal velocity $V_{x}$ develops) at some distance from the entrance (left) surface of the pipe (Figure 3). So, from Figure 4 it is seen that for the quasi-parabolic velocity profile of the incoming flow the zone of the steady motion begins earlier than for the rectangular profile.

Further, we will consider the results obtained for the velocity profiles of the incoming flow calculated in accordance to (14) and (15).

Consider the flow turbulence intensity being the ratio of the root-mean-square fluctuation velocity $u^{\prime}$ to the average flow velocity $u_{\text {avg }}$ (Figure 5).

$$
I=\frac{u^{\prime}}{u_{a v g}}
$$

At the surface of the incoming flow, the turbulence intensity is calculated by the formula 


$$
I=0.16\left(\operatorname{Re}_{D_{H}}\right)^{-\frac{1}{8}}, \operatorname{Re}_{D_{H}}=\frac{v_{0} D_{H}}{v},
$$

where $D_{H}$ is the hydraulic diameter (for the round cross section: $D_{H}=2 r_{1}=0.612 \mathrm{~m}$ ), $v_{0}$ is the incoming flow velocity, and $v$ is the kinematic viscosity of oil $\left(v=1.4 \cdot 10^{-4} \mathrm{~m}^{2} / \mathrm{sec}\right)$.

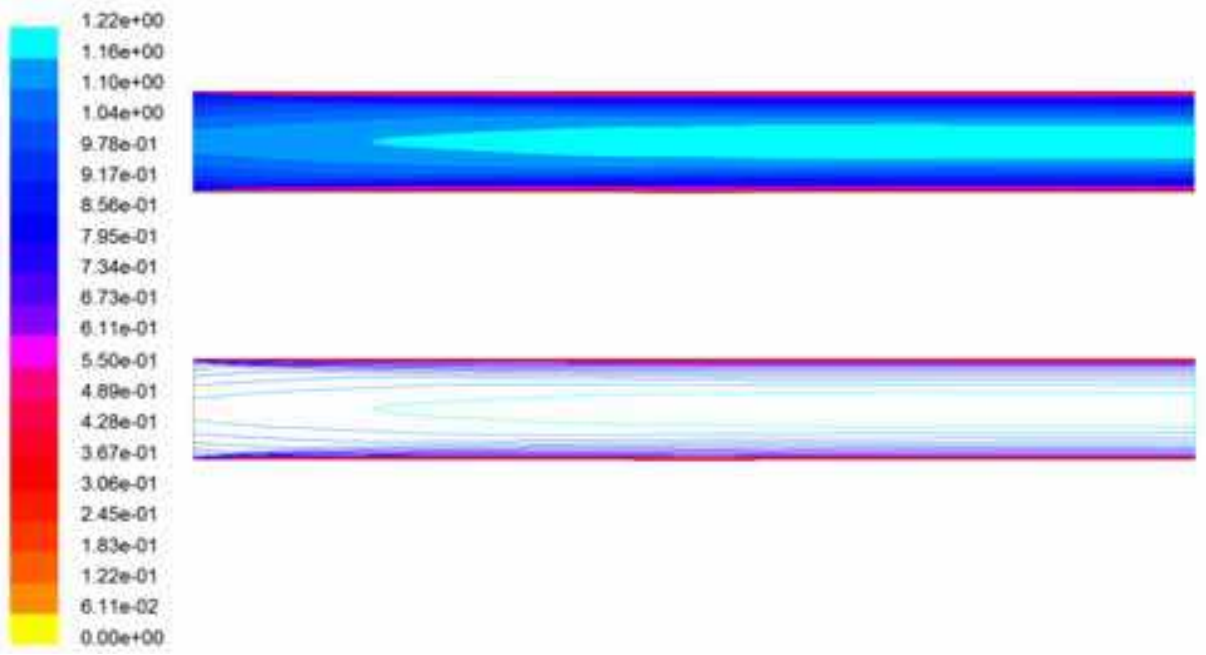

Fig. 3. Longitudinal velocity $V_{x}$ (two-dimensional flow) for the quasi-parabolic turbulent velocity profile of the incoming flow at $\mathrm{v}_{0}=1 \mathrm{~m} / \mathrm{sec}$
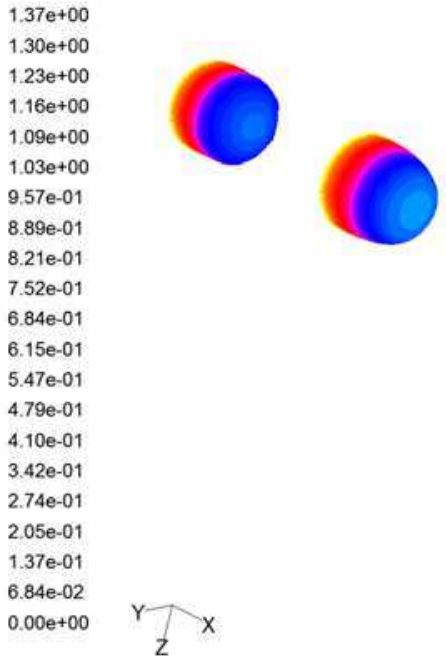

Fig. 4. Profiles of the longitudinal velocity $V_{x}$. over the pipe cross sections (three-dimensional flow) for the quasi-parabolic turbulent velocity profile of the incoming flow at $v_{0}=1 \mathrm{~m} / \mathrm{sec}$ 


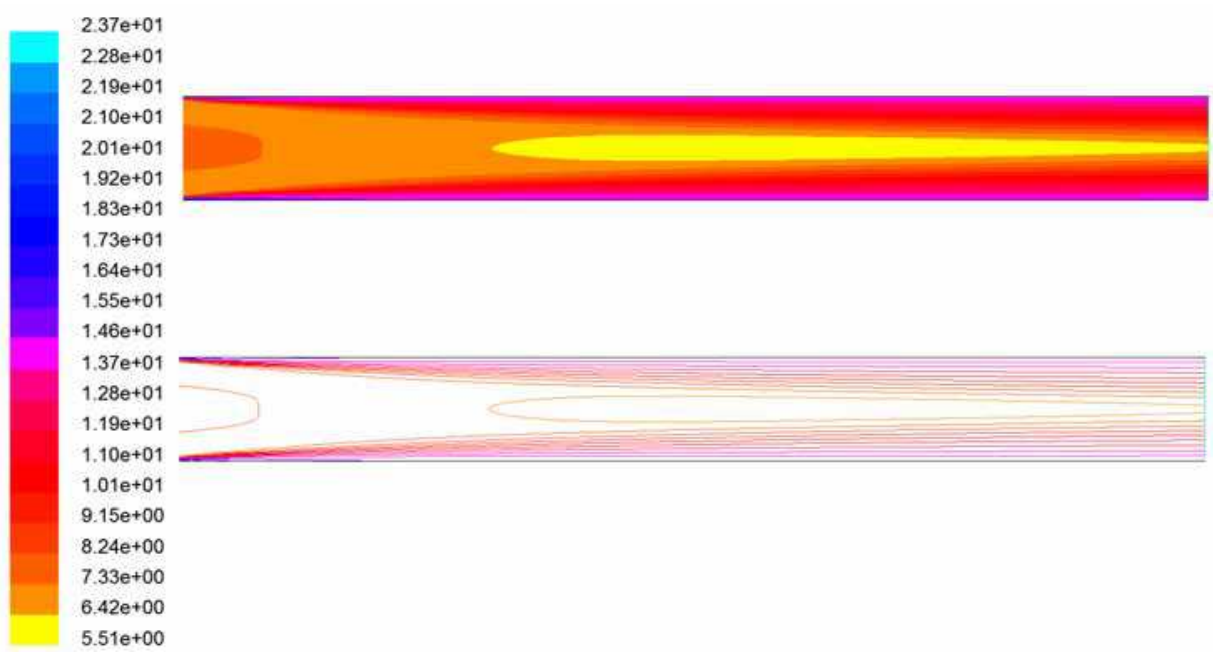

Fig. 5. Turbulence intensity (two-dimensional pipe flow, quasi-parabolic turbulent velocity profile, $v 0=1 \mathrm{~m} / \mathrm{sec}$ )

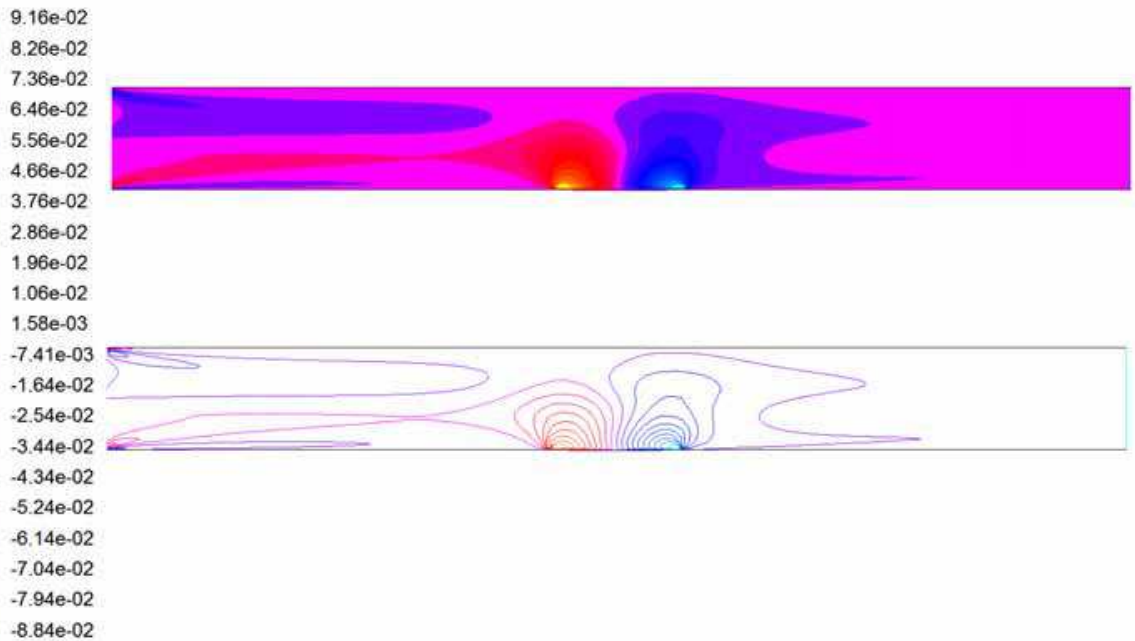

Fig. 6. Transverse velocity $V_{y}$ for the two-dimensional flow in the pipe with corrosion damage at $\mathrm{v} 0=10 \mathrm{~m} / \mathrm{sec}$

The zone of the unsteady turbulent motion is characterized by the higher turbulence intensity (vortex formation) in comparison with the remaining region of the pipe (Figure 5). The highest intensity is observed in the steady motion zone, which is especially noticeable in the calculations with the initial velocity of $1 \mathrm{~m} / \mathrm{sec}$ in the pipe wall region, whereas the lowest one - at the flow symmetry axis.

At high initial flow velocity values the vortex formation rate is higher. 
It should be emphasized that at a higher value of the initial flow velocity, the instability region is longer: at $v_{0}=1 \mathrm{~m} / \mathrm{sec}$ its length is about $2 \mathrm{~m}$, while at $v_{0}=10 \mathrm{~m} / \mathrm{sec}$ its length is about $5 \mathrm{~m}$.

The behavior of the motion (steady or unsteady) exerts an influence on the value of wall stresses. In the unsteady motion zone, they are essentially higher as against the appropriate stresses in the identical steady motion zone.

These figures illustrate that at that place of the pipe, where the fluid motion becomes steady, the value of tangential stress at $v_{0}=1 \mathrm{~m} / \mathrm{sec}$ is approximately equal to $8 \mathrm{~Pa}$, whereas at $v_{0}=$ $10 \mathrm{~m} / \mathrm{sec}$ it is about $240 \mathrm{~Pa}$.

The results as presented above are peculiar for a pipe with corrosion damage and without it. At the same time, the presence of corrosion damage affects the kinematics of the moving flow in calculations with both the rectangular profile of the initial flow velocity and the quasi-parabolic turbulent one. In this domain of geometry, there appear transverse displacements that form a recirculation zone (Figure 7).

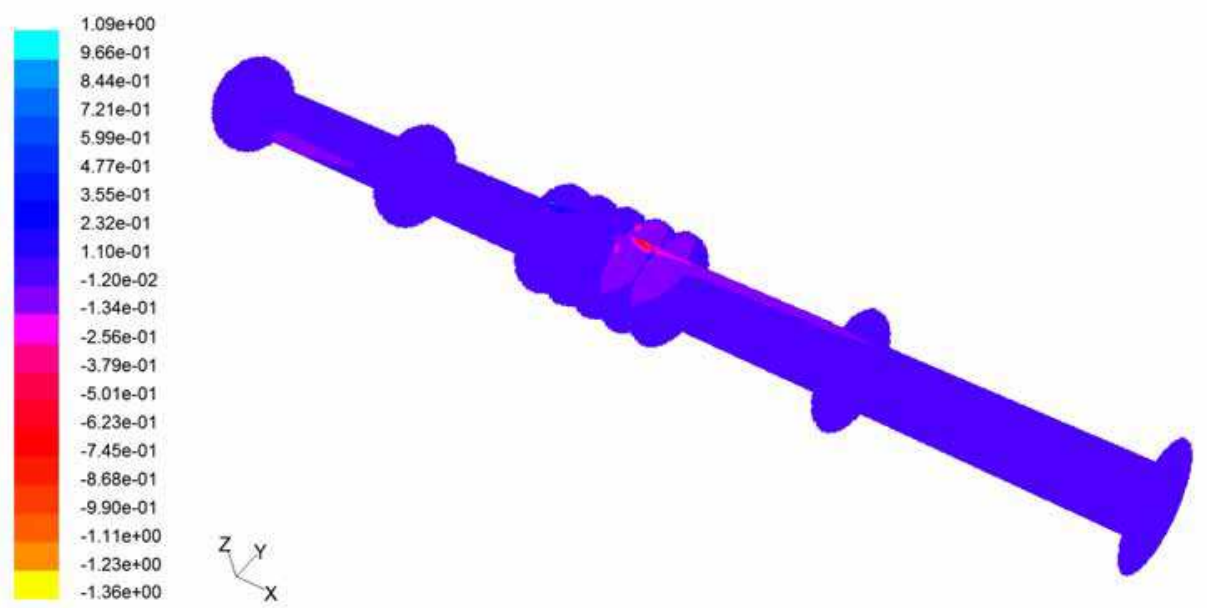

Fig. 7. Transverse velocity $V_{z}$ for the three-dimensional flow in the pipe with corrosion damage at $\mathrm{v}_{0}=10 \mathrm{~m} / \mathrm{sec}$

The corrosion spot exerts a profound effect on changes in wall tangential stresses in the area of the pipe corrosion damage.

Figures 8 and 9 demonstrate that in the corrosion damage area, the values of wall tangential stresses undergo jumping.

For the laminar fluid motion, the value of tangential stresses at the pipe wall is calculated by the following formula [Sedov, 2004]:

$$
\tau_{0}=\mu\left(\frac{\partial v_{x}}{\partial y}+\frac{\partial v_{y}}{\partial x}\right)=\mu \frac{d v}{d r}=\frac{4 \mu v_{0}}{r_{0}},
$$

where $\mu=v \cdot \rho=1.4 \cdot 10^{-4.865}=0.1211 \mathrm{~kg} /\left(\mathrm{m}^{*} \mathrm{sec}\right)$ is the molecular viscosity, $r_{0}=0.306 \mathrm{~m}$ is the pipe radius. 


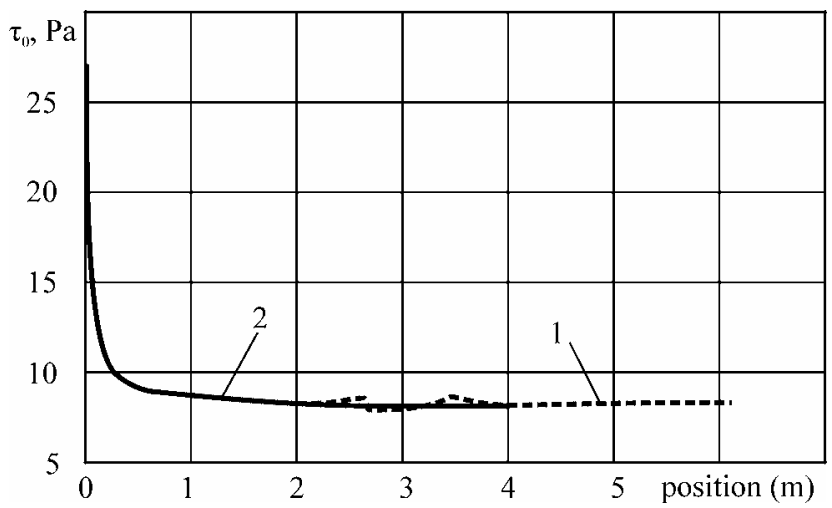

Fig. 8. Wall tangential stresses at the pipe wall: stresses at $y=f(x)$, stresses at $y=2 r_{1}$ for the two-dimensional flow in the pipe with corrosion damage at $v_{0}=1 \mathrm{~m} / \mathrm{sec}$

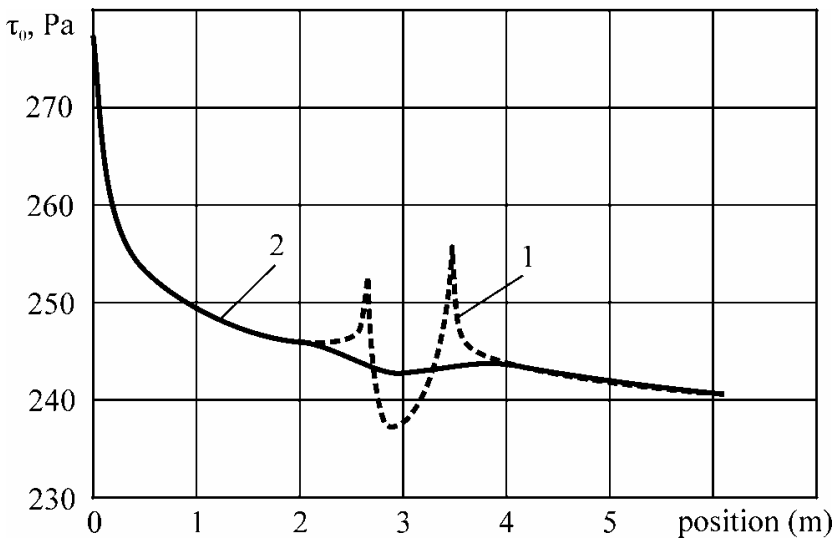

Fig. 9. Wall tangential stresses at the pipe wall: stresses at $y=f(x)$, stresses at $y=2 r_{1}$ for the two-dimensional flow in the pipe with corrosion damage at $v_{0}=10 \mathrm{~m} / \mathrm{sec}$

Then $\tau_{0}$ for the velocities $v_{0}=10 \mathrm{~m} / \mathrm{sec}$ and $v_{0}=1 \mathrm{~m} / \mathrm{sec}$ will be

$$
\tau_{0}^{10}=\frac{4 \cdot 0.1211 \cdot 10}{0.306}=15.83 \mathrm{~Pa}, \tau_{0}^{1}=\frac{4 \cdot 0.1211 \cdot 1}{0.306}=1.58 \mathrm{~Pa} .
$$

The expression for the tangential stresses with regard to the turbulence is of the form [Sedov, 2004]:

$$
\tau_{x y}=\tau_{0}+\tau_{x y}^{\prime}=\mu\left(\frac{\partial \bar{v}_{x}}{\partial y}+\frac{\partial \bar{v}_{y}}{\partial x}\right)-\rho{\overline{v_{x}^{\prime} v_{y}^{\prime}}}_{x}\left(\mu+\mu_{t}\right)\left(\frac{\partial \bar{v}_{x}}{\partial y}+\frac{\partial \bar{v}_{y}}{\partial x}\right) .
$$

The last formula and the analysis of the calculations enable evaluating the turbulence influence on the value of tangential stresses at the pipe wall. As indicated above, at different profiles and initial velocity values the tangential stresses were obtained: at $v_{0}=1 \mathrm{~m} / \mathrm{sec}$ : 
$\tau_{x y}=\tau_{w} \approx 8 \mathrm{~Pa}$, at $\mathrm{v}_{0}=10 \mathrm{~m} / \mathrm{sec}: \tau_{x y}=\tau_{w} \approx 240 \mathrm{~Pa}$. The value of the turbulent stress (Reynolds stress):

at $\mathrm{v}_{0}=1 \mathrm{~m} / \mathrm{sec}$ :

$$
\tau_{x y}^{\prime}=-\rho \overline{v_{x}^{\prime} v_{y}^{\prime}}=\mu_{t}\left(\frac{\partial \bar{v}_{x}}{\partial y}+\frac{\partial \bar{v}_{y}}{\partial x}\right)=\tau_{x y}-\tau_{0}=8-1.58=6.42 \mathrm{~Pa},
$$

at $\mathrm{v}_{0}=10 \mathrm{~m} / \mathrm{sec}$ :

$$
\begin{aligned}
\tau_{x y}^{\prime} & =-\rho \overline{v_{x}^{\prime} v_{y}^{\prime}}=\mu_{t}\left(\frac{\partial \bar{v}_{x}}{\partial y}+\frac{\partial \bar{v}_{y}}{\partial x}\right)=\tau_{x y}-\tau_{0}= \\
& =240-15.83=224.17 \mathrm{~Pa},
\end{aligned}
$$

The results obtained are evident of the fact that the turbulence much contributes to the formation of wall tangential stresses. At the higher turbulence intensity (it is especially high in the pipe wall region), Reynolds stresses increase, too. I.e., the turbulence stresses are:

$$
\begin{gathered}
\text { at } \mathrm{v}_{0}=1 \mathrm{~m} / \mathrm{sec}: \frac{\tau_{x y}-\tau_{0}}{\tau_{x y}} 100 \%=\frac{8-1.58}{8} 100 \%=80.25 \% ; \\
\text { at } \mathrm{v}_{0}=10 \mathrm{~m} / \mathrm{sec}: \frac{\tau_{x y}-\tau_{0}}{\tau_{x y}} 100 \%=\frac{240-15.83}{240} 100 \%=93.4 \% .
\end{gathered}
$$

The analysis as made above shows that the calculation of the motion of a viscous fluid in the pipe as laminar can result in a highly distorted distribution pattern of the tangential stresses at the inner surface of the pipe. It can be concluded that the analysis of viscous fluid friction, when the flow interacts with the pipe wall, must be performed on the basis of the calculation of flow motion as essentially turbulent one.

\section{Analytical solutions for the stress-strain state of the pipeline model under the action of internal pressure and temperature difference}

In the simplified analytical statement, the problem of calculating the stress-strain state of a long cylindrical pipe reduces to the problem of the strain of a thin ring loaded with a pressure $p_{1}$ uniformly distributed over its inner wall and also with a pressure $p_{2}$ uniformly distributed over the outer surface of the ring (Figure 10). Operating conditions of the ring do not vary depending on whether it is considered either as isolated or as a part of the long cylinder.

Work [Ponomarev et al., 1958] and many other publications contain the classical solution to this problem based on solving the following differential equation for radial displacements:

$$
\frac{d^{2} u_{r}}{d r^{2}}+\frac{1}{r} \frac{d u_{r}}{d r}-\frac{1}{r^{2}} u_{r}=0
$$

The general solution of this equation is of the form:

$$
u_{r}=C_{1} r+C_{2} \frac{1}{r}
$$


With the use of the relationship between stresses and strains, and also of Hook's law, it is possible to determine integration constants $C_{1}$ and $C_{2}$ under the boundary conditions of the form:

$$
\begin{gathered}
\left.\sigma_{r}\right|_{r=r_{1}}=-p_{1}, \\
\left.\sigma_{r}\right|_{r=r_{2}}=-p_{2} .
\end{gathered}
$$

where $p_{1}$ is the internal pressure; $p_{2}$ is the external pressure.
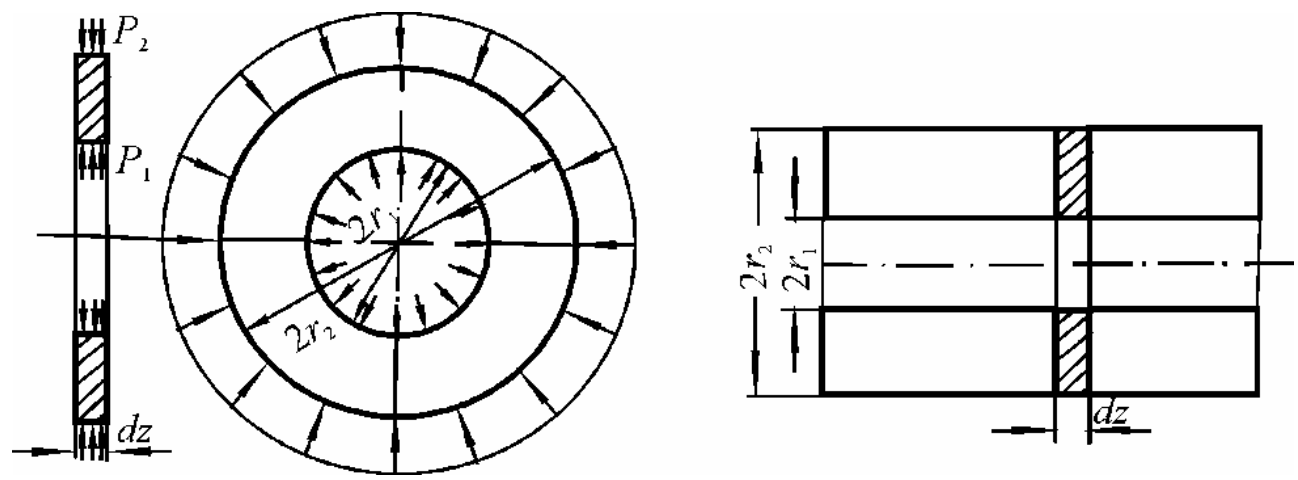

Fig. 10. Loading diagram of the circular cavity of the pipe

In such a case, the general formulas for stresses at any pipe point have the following form:

$$
\begin{gathered}
\sigma_{r}=\frac{p_{1} r_{1}^{2}-p_{2} r_{2}^{2}}{r_{2}^{2}-r_{1}^{2}}-\frac{\left(p_{1}-p_{2}\right) r_{1}^{2} r_{2}^{2}}{r_{2}^{2}-r_{1}^{2}} \frac{1}{r^{2}}, \\
\sigma_{\varphi}=\frac{p_{1} r_{1}^{2}-p_{2} r_{2}^{2}}{r_{2}^{2}-r_{1}^{2}}+\frac{\left(p_{1}-p_{2}\right) r_{1}^{2} r_{2}^{2}}{r_{2}^{2}-r_{1}^{2}} \frac{1}{r^{2}} .
\end{gathered}
$$

Assuming that the cylinder is loaded only with the internal pressure $\left(p_{1}=p, p_{2}=0\right)$, the following expressions are obtained for the stresses based on the internal pressure:

$$
\frac{\sigma_{r}^{(p)}}{p}=\frac{1}{k_{r 2}^{2}}\left(\frac{k_{r 12}^{2}}{1-k_{r 12}^{2}}-1\right), \frac{\sigma_{\varphi}^{(p)}}{p}=\frac{1}{k_{r 2}^{2}}\left(\frac{k_{r 12}^{2}}{1-k_{r 12}^{2}}+1\right),
$$

where $k_{r 2}=r / r_{2}, k_{r 12}=r_{1} / r_{2}$

To analyze the rigid fixing of the outer surface of the pipeline, as one of the equations of the boundary conditions we choose expression (26) for displacements, the value of which tends to zero at the outer surface of the model. As the secondary boundary condition we use an expression for stresses at the inner surface of the cylinder from (27):

$$
\left.\sigma_{r}\right|_{r=r_{1}}=-p_{1},\left.u_{r}\right|_{r=r_{2}}=0
$$

Then, the expressions for the stresses will assume the form: 


$$
\begin{gathered}
\frac{\sigma_{r}^{(p)}}{p}=-\frac{k_{r 12}^{2}}{k_{r 2}^{2}} \frac{k_{r 2}^{2}\left(1+v_{1}\right)-\left(v_{1}-1\right)}{k_{r 12}^{2}\left(1+v_{1}\right)-\left(v_{1}-1\right)}, \\
\frac{\sigma_{\varphi}^{(p)}}{p}=-\frac{k_{r 12}^{2}}{k_{r 2}^{2}} \frac{k_{r 2}^{2}\left(1+v_{1}\right)+\left(v_{1}-1\right)}{k_{r 12}^{2}\left(1+v_{1}\right)-\left(v_{1}-1\right)} .
\end{gathered}
$$

Consider a long thick-wall pipe, whose wall temperature $t$ varies across the wall, but is constant along the pipe, i. e., $t=t(r)$ [Ponomarev et al., 1958].

If the heat flux is steady and if the temperature of the outer surface of the pipe is equal to zero and that of the inner surface is designated as $T$, then from the theory of heat transfer it follows that the dependence of the temperature $t$ on the radius $r$ is given by the formula

$$
t=\frac{T}{\ln k_{r 12}} \ln k_{r 2}
$$

Any other boundary conditions can be obtained by making uniform heating or cooling, which does not cause any stresses. Thus, the quantity $T$ in essence represents the temperature difference $\Delta T$ of the inner and outer surfaces of the pipe.

As the temperature is constant along the pipe, it can be considered that cross sections at a sufficient distance from the pipe ends remain plane, and the strain $\varepsilon_{z}$ is a constant quantity. The temperature influence can be taken into account if the strains due to stresses are added with the uniform temperature expansion $\Delta \varepsilon=\alpha \Delta T$ where $\alpha$ is the linear expansion coefficient of material.

The stress-strain state in the presence of the temperature difference between the pipe walls can be determined by solving the differential equation [Ponomarev et al., 1958]:

$$
\frac{d^{2} u}{d r^{2}}+\frac{1}{r} \frac{d u}{d r}-\frac{u}{r^{2}}=\frac{1+v_{1}}{1-v_{1}} \alpha \frac{d t}{d r}
$$

Subject to the boundary conditions

$$
\left.\sigma_{r}\right|_{r=r_{1}}=0,\left.\sigma_{r}\right|_{r=r_{2}}=0 \text {. }
$$

Having solved boundary-value problem (33), (34), the expressions for stresses are of the form:

$$
\begin{aligned}
& \sigma_{r}^{(T)}=\frac{E_{1} \alpha \Delta T}{2(1-v)} \frac{1}{\ln k_{r 12}}\left[-\ln k_{r 2}-\frac{k_{r 12}^{2}}{1-k_{r 12}^{2}}\left(1-\frac{1}{k_{r 2}^{2}}\right) \ln k_{r 12}\right], \\
& \sigma_{\varphi}^{(T)}=\frac{E_{1} \alpha \Delta T}{2(1-v)} \frac{1}{\ln k_{r 12}}\left[-1-\ln k_{r 2}-\frac{k_{r 12}^{2}}{1-k_{r 12}^{2}}\left(1+\frac{1}{k_{r 2}^{2}}\right) \ln k_{r 12}\right], \\
& \sigma_{z}^{(T)}=\frac{E_{1} \alpha \Delta T}{2(1-v)} \frac{1}{\ln k_{r 12}}\left[-1-2 \ln k_{r 2}-\frac{2 k_{r 12}^{2}}{1-k_{r 12}^{2}} \ln k_{r 12}\right],
\end{aligned}
$$

Figures 11-14 show the distribution of dimensionless stresses (29), (31), (35) along $r$ and their sums 


$$
\sigma_{i}^{(p+T)}=\sigma_{i}^{(p)}+\sigma_{i}^{(T)}, i=r, \varphi, z,
$$

for $k_{r 12}=0.8, v=0.3, E_{1} \alpha T / p=10$ (for example, at $E_{1}=2 \cdot 10^{11} \mathrm{~Pa}, \alpha=10-5^{\circ} \mathrm{C}^{-1}, \Delta T=20^{\circ} \mathrm{C}$ ). These figures well illustrate the essential influence of the temperature and the procedure of fixing the pipe on its stress-strain state.

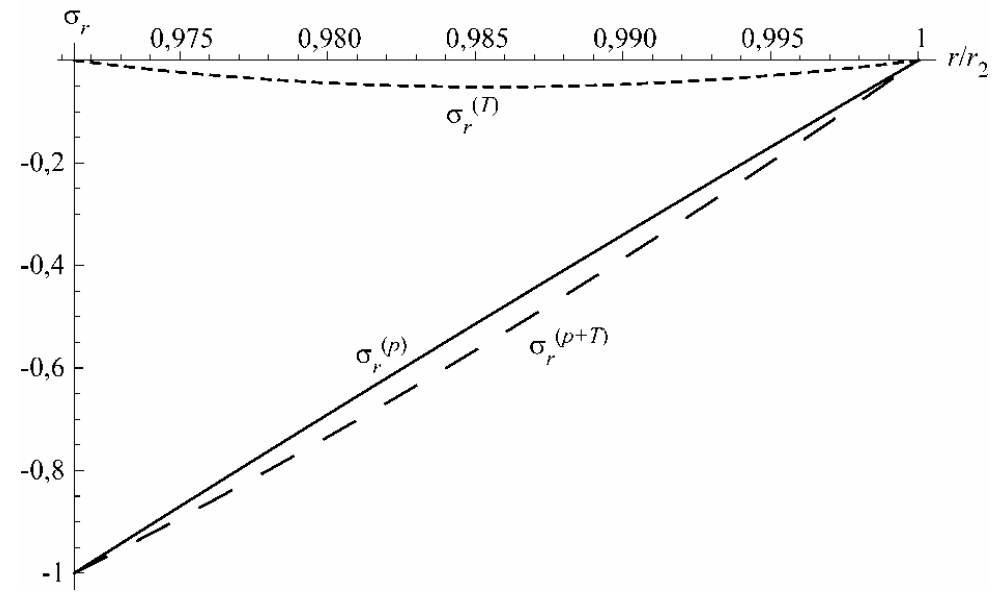

Fig. 11. Radial stresses for problems (25), (27) and (33), (34) at $r 1 \leq r \leq r 2$

Compare the distribution of the stresses calculated analytically with the use of (31) for a non-damaged pipe with the finite-element calculation results by plotting the graphs of the pipe thickness stress distribution (Figures 1.15-1.16). To make calculation, take the following initial data: inner and outer radii $r_{1}=0.306 \mathrm{~m}$ and $r_{2}=0.315 \mathrm{~m}, p_{1}=4 \mathrm{M} \mathrm{Pa}, p_{2}=0, E=2 \cdot 10^{11} \mathrm{~Pa}$, $v=0.3$.

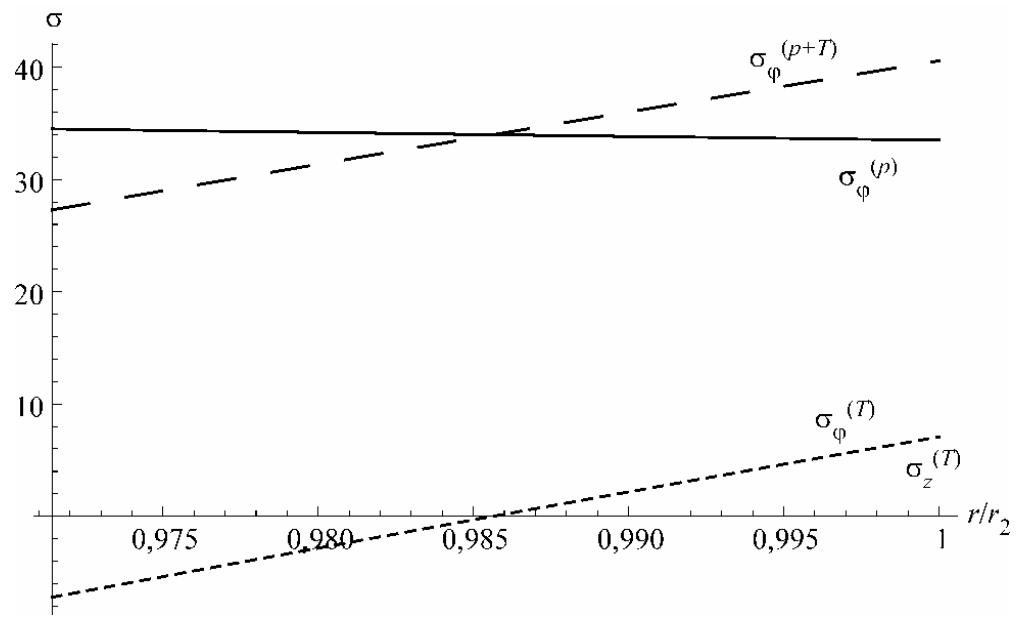

Fig. 12. Circumferential stresses for problems (25), (27) and (33), (34) at $r 1 \leq r \leq r 2$ 


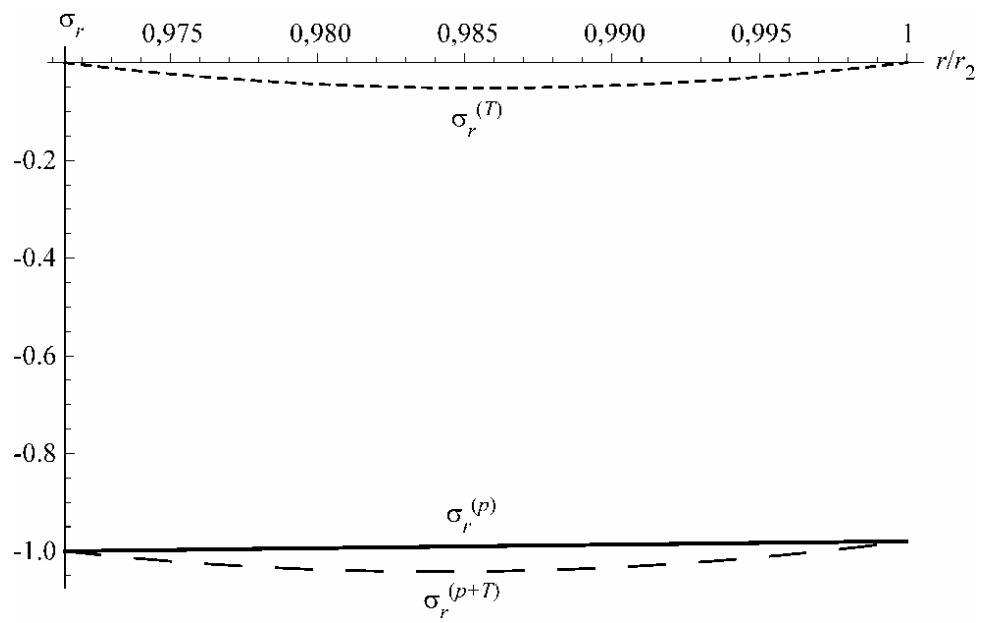

Fig. 13. Longitudinal stresses for problems (25), (30) and (33), (34) at $r 1 \leq r \leq r 2$

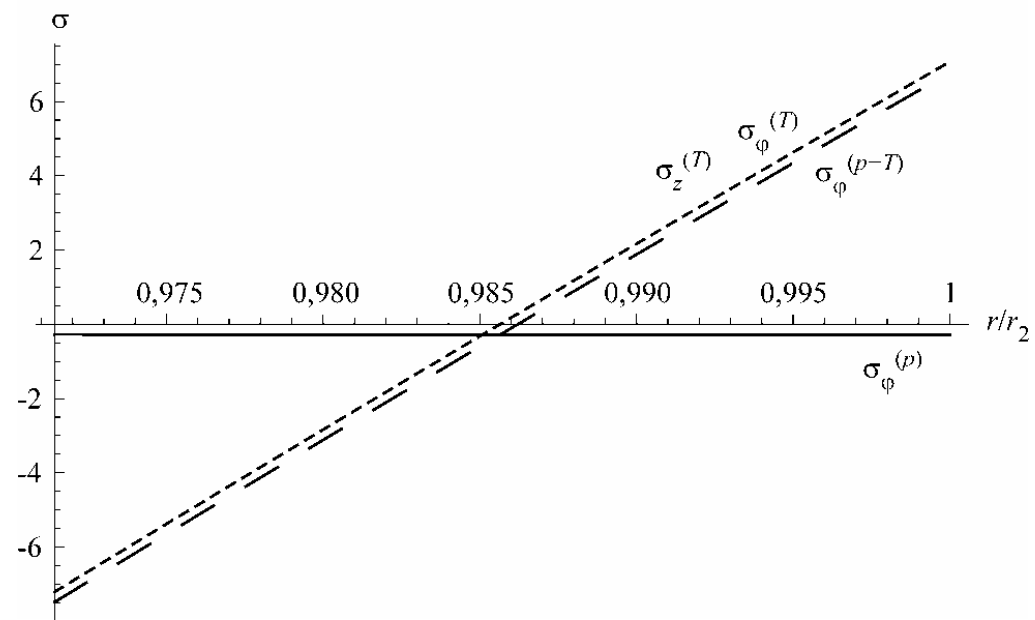

Fig. 14. Circumferential stresses for problems (25), (30) and (33), (34) at $r 1 \leq r \leq r 2$

As seen from Figures 15-16, the $\sigma_{r}$ and $\sigma_{\varphi}$ distributions obtained from the analytical calculation practically fully coincide with those obtained from the finite-element calculation, which points to a very small error of the latter.

\section{Stress-strain state of the three-dimenisonal model of a pipe with corrosion damage under complex loading}

Consider the problem of determining the stress-strain state of a two-dimenaional model of a pipe in the area of three-dimensional elliptical damage.

In calculations we used a model of a pipe with the following geometric characteristics (Figure 2): inner (without damage) and outer radii $r_{1}=0.306 \mathrm{~m}$ and $r_{2}=0.315 \mathrm{~m}$, 


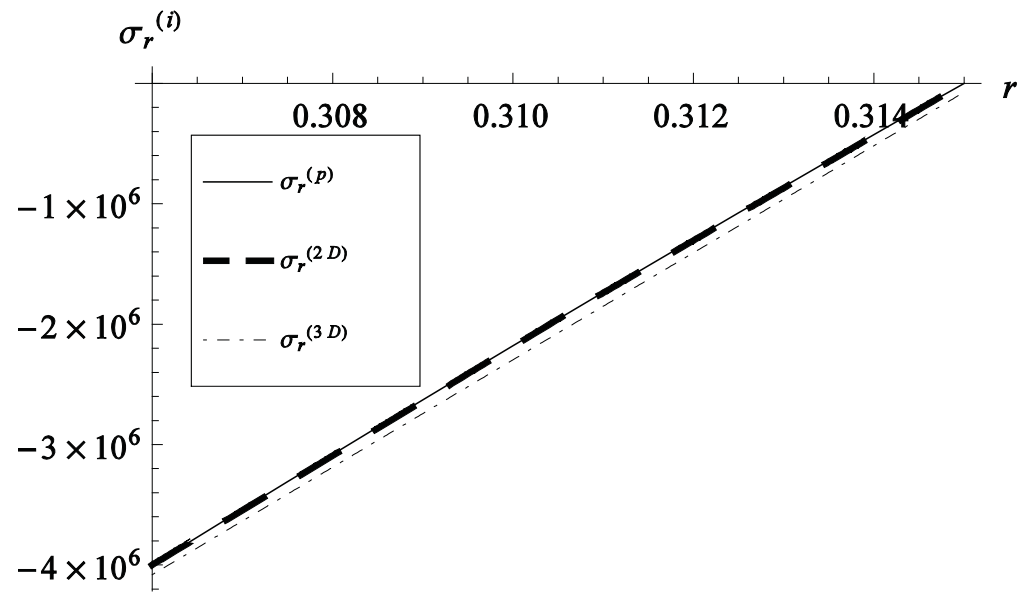

Fig. 15. Radial stress distribution for the analytical calculation $\left(\sigma_{r}^{(p)}\right)$, for the twodimensional computer model $\left(\sigma_{r}^{(2 D)}\right)$, for the three-dimensional computer model $\left(\sigma_{r}^{(3 D)}\right)$

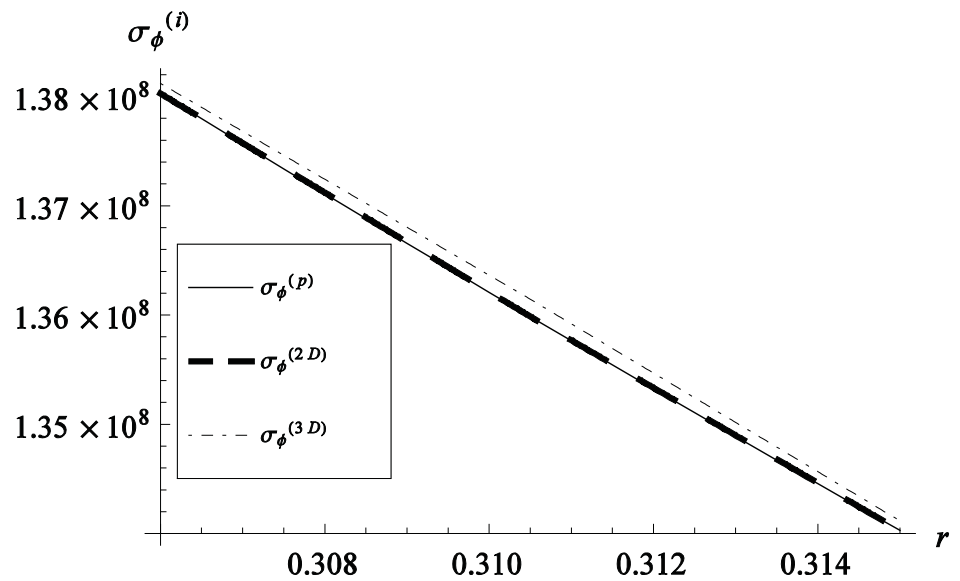

Fig. 16. Circumferential stress distribution for the analytical calculation $\left(\sigma_{\varphi}^{(p)}\right)$, for the twodimensional computer model $\left(\sigma_{\varphi}^{(2 D)}\right)$, for the three-dimensional computer model $\left(\sigma_{\varphi}^{(3 D)}\right)$ respectively, the length of the calculated pipe section $L=3 \mathrm{~m}$, sizes of elliptical corrosion damage length $\times$ width $\times$ depth $-0.8 \mathrm{~m} \times 0.4 \mathrm{~m} \times 0.0034 \mathrm{~m}$.

The pipe mateial had the following characteristics: elasticity modulus $E_{1}=2 \cdot 10^{11} \mathrm{~Pa}$, Poisson's coefficient $v_{1}=0.3$, temperature expansion coefficient $\alpha=10^{-5}{ }^{\circ} \mathrm{C}^{-1}$, thermal conductivity $k=43 \mathrm{~W} /\left(\mathrm{m}^{\circ} \mathrm{C}\right)$, and the soil parameters were: $E_{2}=1.5 \cdot 10^{9} \mathrm{~Pa}$, Poisson's coefficient $v_{2}=0.5$. The coefficient of friction between the pipe and soil was $\mu=0.5$. The internal pressure in the pipe (1) is:

$$
\left.\sigma_{r}\right|_{r=r_{1}}=p=4 \mathrm{MPa}
$$


The temperature diffference between the pipe walls is (3)

$$
\left|T_{r_{1}}-T_{r_{2}}\right|=\Delta T=20^{\circ} \mathrm{C} \text {. }
$$

The value of internal tangential stresses (wall friction) (2) is determined from the hydrodynamic calculation of the turbulent motion of a viscous fluid in the pipe.

Calculations in the absence of fixing of the outer surface of the pipe and in the presence of the friction force over the inner surface (2) were made for $1 / 2$ of the main model (Figure 2), since in this case (in the presence of friction) the calculation model has only one symmetry plane. In the absence of outer surface fixing, calculations were made for $1 / 4$ of the model of the pipeline section since the boundary conditions of form (2) are also absent and, hence, the model has two symmetry planes.

The investigation of the stress state of the pipe in soil is peformed for $1 / 4$ of the main model of the pipe placed inside a hollow elastic cylinder modeling soil (Figure 17).

In calculations without temperature load, a finite-element grid is composed of 20-node elements SOLID95 (Figure 17) meant for three-dimensional solid calculations. In the presence of temperature difference, a grid is composed of a layer of 10-node finite elements SOLID98 intended for three-dimensional solid and temperature calculations. The size of a finite element (fin length) $a_{F E}=10^{-2} \mathrm{~m}$.
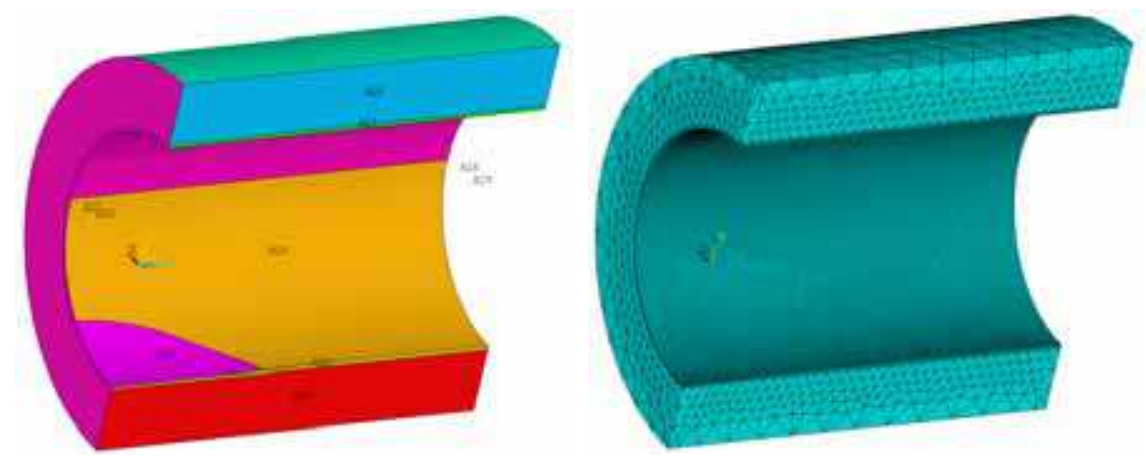

Fig. 17. General view and the finite-element partition of $1 / 4$ of the pipe model in soil

Thus, the pipe wall is composed of one layer of elements since its thickness is less than centermeter. During a compartively small computer time such partition allows obtaining the results that are in good agreement with the analytical ones (see, below).

Calculations for boundary conditions (8) with a description of the contact between the pipe and soil use elements CONTA175 and TARGE170.

As seen from Figure 17, the finite elements are mainly shaped as a prism, the base of which is an equivalateral triangle. The value of the tangential stresses $\left.\tau_{r z}\right|_{r=r_{1}}$ applied to each node of the inner surface will then be calculated as follows:

$$
\left.\tau_{r z}^{(\text {node })}\right|_{r=r_{1}}=\tau_{0} S,
$$

where $S$ is the area of the romb with the side $a_{F E}$ and with the acute angle $\beta_{F E}=\pi / 3$. Thus, the value of the tangential stress applied at one node will be 


$$
\left.\tau_{r z}^{(\text {node })}\right|_{r=r_{1}}=\tau_{0} a_{F E}^{2} \sin \beta_{F E}=260 \cdot 10^{-4} \sqrt{3} / 2=2.25 \cdot 10^{-2} \mathrm{~Pa} .
$$

The analysis of the calculation results will be mainly made for the normal (principal) stresses $\sigma_{x}, \sigma_{y}, \sigma_{z}$ in the Cartesian system of coordinates. It should be noted that for axissymmetrical models, among which is a pipe, the cylindrical system of coordinates is natural, in which the normal stresses in the radial $\sigma_{r}$, circumferential $\sigma_{t}$, and axial $\sigma_{z}$ directions are principal. Since the software ANSYS does not envisage stresses in the polar system of coordinates, the analysis of the stress state will be made on the basis of $\sigma_{x}, \sigma_{y}, \sigma_{z}$ in those domains where they coincide with $\sigma_{r}, \sigma_{t}, \sigma_{z}$ corresponding to the last principal stresses $\sigma_{1}$, $\sigma_{2}, \sigma_{3}$ and also to the tangential stresses $\sigma_{y z}$.

Make a comparative analysis of the results of numerical calculation for boundary conditions (1), (6) and (1), (7) with those of analytical calculation as described in Sect. 1.4. Consider pipe stresses in the circumferential $\sigma_{t}$ and radial $\sigma_{r}$ directions.

Figures 18 and Figure 19 show that in the case of fixing $\left.u_{x}\right|_{r=r_{2}}=\left.u_{y}\right|_{r=r_{2}}=0$, corrosion damage exerts an essential influence on the $\sigma_{t}$ distribution over the inner surface of the pipe. At the damage edge, the absolute value of circumferential $\sigma_{t}$ is, on average, by $15 \%$ higher than the one at the inner surface of the pipe with damage and, on average, by $30 \%$ higher than the one inside damage. In the case of fixing $\left.u_{x}\right|_{r=r_{2}}=\left.u_{y}\right|_{r=r_{2}}=\left.u_{z}\right|_{r=r_{2}}=0$, the $\sigma_{t}$ distributions are localized just in the damage area. The additional key condition $\left.u_{z}\right|_{r=r_{2}}=0$ (coupling along the $z$-axis) is expressed in increasing $\left|\sigma_{t}\right|$ at the inner surface without damage in the calculation for (1), (7) approximately by $60 \%$ in comparison with the calculation for (1), (6). However in the calculation for (1), (7), the $\left|\sigma_{t}\right|$ differences between the damage edge, the inner surface without damage, and the inner surface with damage are, on average, only 6 and 3\%, respectively. Maximum and minimum values of $\sigma_{t}$ in the calculation for (1), (6) are: $\sigma_{t}^{\min }=-1.27 \cdot 10^{6} \mathrm{~Pa}$ and $\sigma_{t}^{\max }=-7.96 \cdot 10^{5} \mathrm{~Pa}$; in the calculation for (1), (7) are: $\sigma_{t}^{\min }=-1.72 \cdot 10^{6} \mathrm{~Pa}$ and $\sigma_{t}^{\max }=-1.61 \cdot 10^{6} \mathrm{~Pa}$.

The analysis of the stress distribution reveals a good coincidence of the results of the analytical and finite-element calculations for $\sigma_{t}$. At $r_{1} \leq y \leq r_{2}, x=z=0$ in the vicinity of the pipe without damage, the error is at $r=r_{1}$

$$
e=\frac{1.093-1.082}{1.093} \cdot 100 \%=1.03 \%
$$

at $r=r_{2}$

$$
e=\frac{1.175-1.165}{1.175} \cdot 100 \%=0.94 \% .
$$

Thus, at the upper inner surface of the pipe the damage influence on the $\sigma_{t}$ variation is inconsiderable. A comparatively small error as obtained above is attributed to the fact that the three-dimensional calculation subject to (1), (6) was made at the same key conditions as the analytical calculation of the two-dimensional model. At the same time, owing to the additonal condition $\left.u_{z}\right|_{r=r_{2}}=0$ the difference between the results of the analytical calculation and the calculation for (1), (7) is much greater - about $45 \%$. 


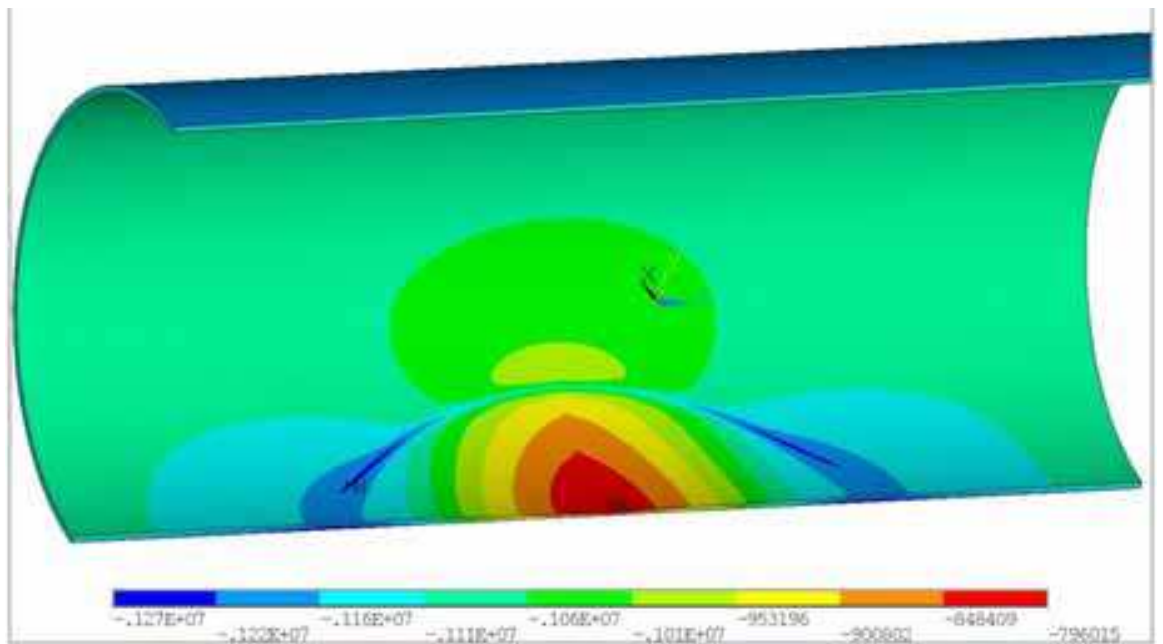

Fig. 18. Distribution of the stress $\sigma_{2}\left(\sigma_{t}\right)$ at $\left.\sigma_{r}\right|_{r=r_{1}}=p,\left.u_{x}\right|_{r=r_{2}}=\left.u_{y}\right|_{r=r_{2}}=0$

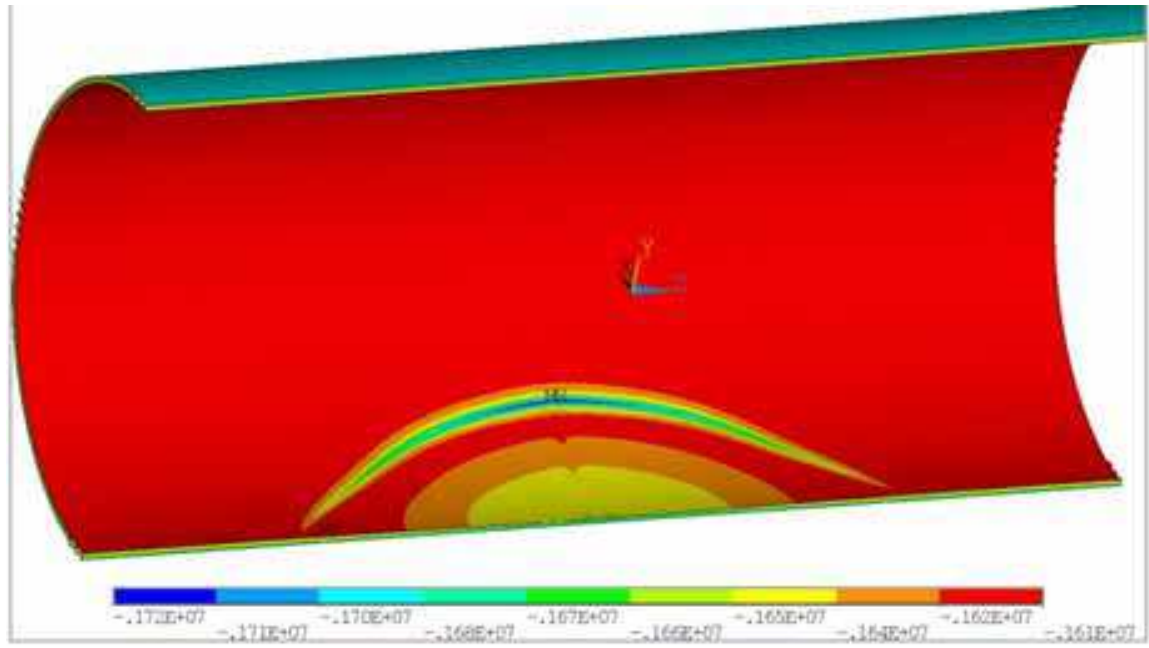

Fig. 19. Distribution of the stress $\sigma_{1}\left(\sigma_{t}\right)$ at $\left.\sigma_{r}\right|_{r=r_{1}}=p,\left.u_{x}\right|_{r=r_{2}}=\left.u_{y}\right|_{r=r_{2}}=\left.u_{z}\right|_{r=r_{2}}=0$

A more detailed analysis of the stress-strain state can be made for distributions along the below paths.

For $1 / 2$ of the pipe model:

Path 1 . Along the straight line $r_{1} \leq y \leq r_{2}$ at $x=z=0$ :

from $P_{11}\left(0, r_{1}, 0\right)$ to $P_{12}\left(0, r_{2}, 0\right)$.

Path 2. Corrosion damage center $\left(-r_{1}-h \leq y \leq-r_{2}\right.$ at $\left.x=z=0\right)$ :

from $P_{21}\left(0,-r_{1}-h, 0\right)$ to $P_{22}\left(0,-r_{2}, 0\right)$. 
Path 3. Cavity boundary over the cross section $z=0$ :

from $P_{31}(0.186,-0.243,0)$ to $P_{32}(0.192,-0.25,0)$.

Path 4 . Cavity boundary over the cross section $x=0$ :

from $P_{41}\left(0,-r_{1}, d / 2\right)$ to $P_{42}\left(0,-r_{2}, d / 2\right)$.

Path 5. Along the straight line of the upper inner surface of the pipe $-0.8 L / 2 \leq z \leq 0.8 L / 2$ at $x=0, y=r_{1}$ : from $P_{51}\left(0, r_{1},-0.8 L / 2\right)$ to $P_{52}\left(0, r_{1}, 0.8 L / 2\right)$.

Path 6. Along the curve of the lower inner surface of the pipe $-0.8 L / 2 \leq z \leq 0.8 L / 2$ at $x=0$, $y=\left\{\begin{array}{l}-r_{1}=f(z), 0 \leq|z| \leq d / 2 \\ -r_{1}, d / 2 \leq|z| \leq 0.8 L / 2\end{array}\right.$ through the points:

$P_{64}\left(0,-r_{1},-0.8 L / 2\right), P_{63}\left(0,-r_{1},-d / 2\right), P_{62}\left(0,-r_{1},-0.0025,-0.2\right), P_{61}\left(0,-r_{1},-h, 0\right), P_{62}\left(0,-r_{1},-\right.$ $0.0025,0.2), P_{63}\left(0,-r_{1}, d / 2\right), P_{64}\left(0,-r_{1}, 0.8 L / 2\right)$.

For $1 / 4$ of the pipe model, paths $1-4$ are the same as those for $1 / 2$, whereas paths 5 and 6 are of the form:

Path 5. Along the strainght upper inner surface of the pipe $0 \leq z \leq 0.8 L / 2$ at $x=0, y=r_{1}$ : from $P_{51}\left(0, r_{1}, 0\right)$ to $P_{52}\left(0, r_{1}, 0.8 L / 2\right)$.

Path 6. Along the curve of the lower inner surface of the pipe $0 \leq z \leq 0.8 L / 2$ at $x=0$, $y=\left\{\begin{array}{l}-r_{1}=f(z), 0 \leq z \leq d / 2 \\ -r_{1}, d / 2 \leq z \leq 0.8 L / 2\end{array}\right.$ through the points:

$P_{61}\left(0,-r_{1},-h, 0\right), P_{62}\left(0,-r_{1},-0.0025,0.2\right), P_{63}\left(0,-r_{1}, d / 2\right), P_{64}\left(0,-r_{1}, 0.8 L / 2\right)$.

In the above descriptions of the paths, $d=0.8 \mathrm{~m}$ is the length of corrosion damage along the $z$ axis of the pipe. The function $f(z)$ describes the inhomogeneity of the geometry of the inner surface of the pipe with corrosion damage.

The analysis of the distributions shows that $\left|\sigma_{t}\right|$ increases up to $10 \%$ from the inner to the outer surface along paths 1,2, 4 and decreases up to $2 \%$ along path 3 . Thus, it is seen that at the corrosion damage edge over the cross section (path 3), the $\left|\sigma_{t}\right|$ distribution has a specific pattern. It should also be mentioned that if in the calculation for (1), (6), $\left|\sigma_{t}\right|$ inside the damage is approximately by $20 \%$ less than the one at the inner surface without damage, then in the calculation for (1), (7) this stress is approximately by $2 \%$ higher.

Figure 20 shows the $\sigma_{r}$ distribution that is very similar to those in the calculations for (1), (6) and for (1), (7). I.e., the procedure of fixing the outer surface of the pipe practically does not influencesthe $\sigma_{r}$ distribution. At the corrorion damage edge of the inner surface of the pipe, the $\sigma_{r}$ distribution undergoes small variation (up to $1 \%$ ). Maximum and minimum values of $\sigma_{r}$ in the calculation for (1), (6) are: $\sigma_{r}^{\min }=-4.02 \cdot 10^{6} \mathrm{~Pa}$ and $\sigma_{r}^{\max }=-3.91 \cdot 10^{6} \mathrm{~Pa}$; in the calculation for (1), (7): $\sigma_{r}^{\min }=-4.02 \cdot 10^{6} \quad \mathrm{~Pa}$ and $\sigma_{r}^{\max }=-3.92 \cdot 10^{6} \mathrm{~Pa}$.

The numerical analysis of the resuts reveals a good agreement between the results of analytical and finite-element calculations for $\sigma_{r}((1),(6))$. For $r_{1} \leq y \leq r_{2}, x=z=0$ in the region of the pipe without damage at $r=r_{1} e$ is $>>1 \%$, whereas at $r=r_{2} e$ is $\approx 1 \%$ for (1), (6).

Make a comparative analysis of the results of these numerical calculations for (1), and (1), (8) with those of the analytical calculation described in Sect. 1.4 for the boundary conditions of the form $\left.\sigma_{r}\right|_{r=r_{1}}=p,\left.\sigma_{r}\right|_{r=r_{2}}=0$. Consider pipe stresses in the circumfrenetial $\sigma_{t}$ and radial $\sigma_{r}$ directions under the action of internal pressure (1) for fixing absent at the outer surface and at the contact between the the pipe and soil (1), (8). 


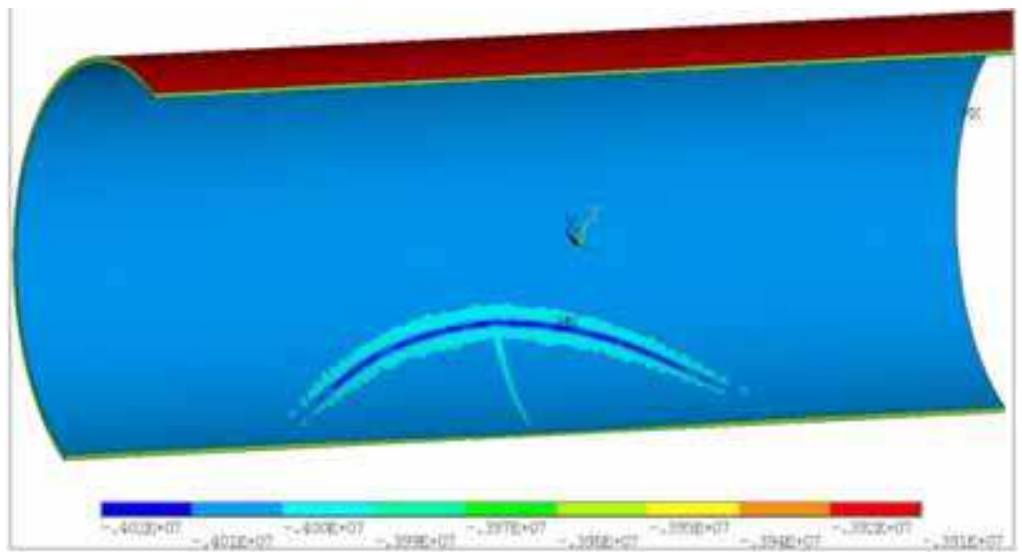

Fig. 20. Distribution of the stress $\sigma_{3}\left(\sigma_{r}\right)$ at $\left.\sigma_{r}\right|_{r=r_{1}}=p,\left.u_{x}\right|_{r=r_{2}}=\left.u_{y}\right|_{r=r_{2}}=0$

From Figures 21 and 22 it is seen that in the case of pipe fixing $\left.u_{x}\right|_{r=r_{2}}=\left.u_{y}\right|_{r=r_{2}}=0$ the corrosion damage exerts an essential influence on the $\sigma_{t}$ distribution over the inner surface of the pipe. The minimum of the tensile stress $\sigma_{t}$ is at the damage edge over the cross section, whereas the maximum - inside the damage. The $\sigma_{t}$ value at the damage edge is, on average, by $30 \%$ less than the one at the inner surface of the pipe without damage and by $60 \%$ less than the one inside the damage. The stress $\sigma_{t}$ is approximately by $50 \%$ less at the surface without damage as against the one inside the damage. At the contact between the pipe and soil, the $\sigma_{t}$ disturbances are localized just in the damage area. In the calculation for $(1),(8)$, the $\sigma_{t}$ differences between the damage edge, the inner surface without damage, and the damage interior are, on average, 60 and $70 \%$, respectively. The stress $\sigma_{t}$ is approximately by $30 \%$ less at the surface without damage as against the one inside the damage. In this calculation there appear essential end disturbances of $\sigma_{t}$. Such a disturbance is the drawback of the calculation involvingh the modeling of the contact between the pipe and soil. Additional investigations are needed to eliminate this disturbance. On the whole, $\sigma_{t}$ at the inner surface of the pipe in the calculation for (1) is, on average, by $70 \%$ larger than the one in the calculation for (1), (8). Maximum and minimum values of $\sigma_{r}$ in the calculation for (1) are: $\sigma_{t}^{\min }=8.39 \cdot 10^{7} \mathrm{~Pa}$ and $\sigma_{t}^{\max }=6.65 \cdot 10^{8} \mathrm{~Pa}$; in the calculation for $(1),(8): \sigma_{t}^{\min }=7.66 \cdot 10^{6}$ $\mathrm{Pa}$ and $\sigma_{t}^{\max }=6.17 \cdot 10^{7} \mathrm{~Pa}$.

The numerical analysis of the results shows not bad coincidence of the results of the analytical and finite-element calculations for $\sigma_{t}$, (1). At $r_{1} \leq y \leq r_{2}, x=z=0$ in the region of the pipe without damage the error at $r=r_{1}$ is approximately equal to

$$
e=\frac{1.38-1.45}{1.38} \cdot 100 \%=-6.71 \% \text {, }
$$

at $r=r_{2}$

$$
e=\frac{1.34-1.305}{1.34} \cdot 100 \%=2.61 \% \text {. }
$$




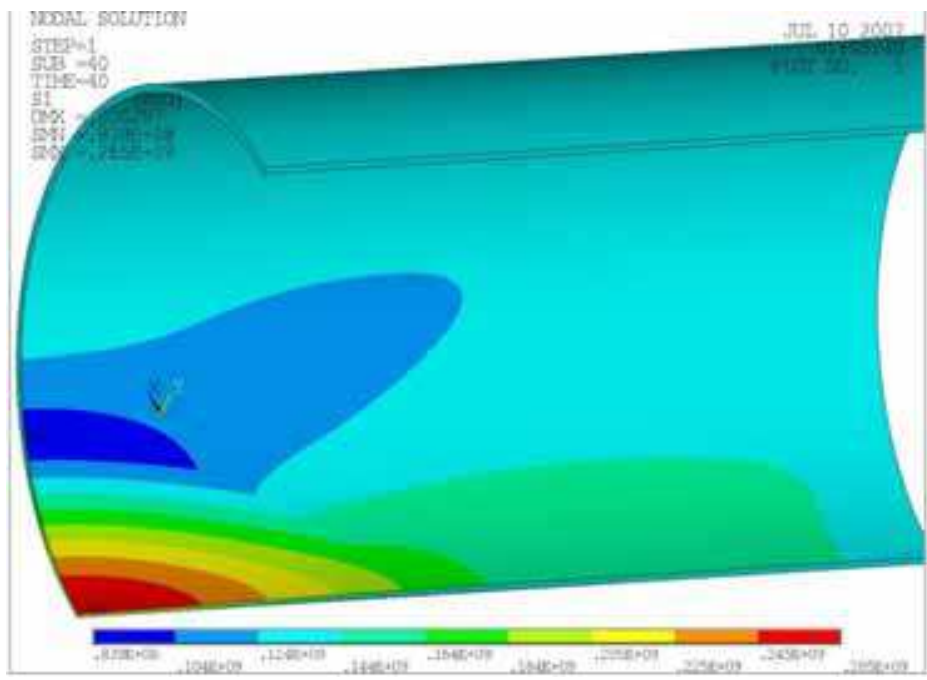

Fig. 21. Distribution of the stress $\sigma_{1}\left(\sigma_{t}\right)$ at $\left.\sigma_{r}\right|_{r=r_{1}}=p$

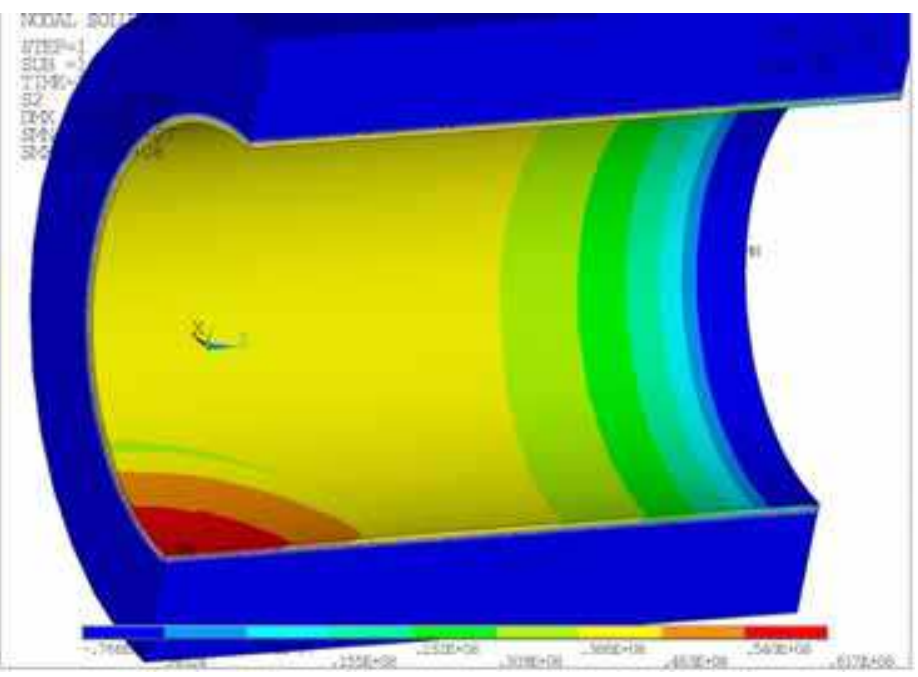

Fig. 22. Distribution of the stress $\sigma_{2}\left(\sigma_{t}\right)$ at $\left.\sigma_{r}\right|_{r=r_{1}}=p,\left.\sigma_{r}^{(1)}\right|_{r=r_{2}}=-\left.\sigma_{r}^{(2)}\right|_{r=r_{2}}$,

$\left.\sigma_{\tau}^{(1)}\right|_{r=r_{2}}=-\left.\sigma_{\tau}^{(2)}\right|_{r=r_{2}}=\left.f \sigma_{n}^{(1)}\right|_{r=r_{2}},\left.u_{x}\right|_{r=r_{3}}=\left.u_{y}\right|_{r=r_{3}}=0$

Thus, at the upper inner surface of the pipe, the damage influence on the $\sigma_{t}$ variation is inconsiderable. A comparatively small error obtained says about the fit of the key condition $\left.\sigma_{r}\right|_{r=r_{1}}=p$ in the three-dimensional calculation with the key condition for the twodimensional model $\left.\sigma_{r}\right|_{r=r_{1}}=p,\left.\sigma_{r}\right|_{r=r_{2}}=0$ in the analytical calculation. For (1), (8), because 
of the presence of elastic soil the difference between the results of the analytical and finiteelement calculations and the calculation for (1), (7) is much larger - about $70 \%$.

The analysis shows that from the inner to the outer surface along paths $1,2,4$, the stress $\sigma_{t}$ decreases approximately by 7,36 and $43 \%$, respectively, and increases approximately by $120 \%$ along path 3 . Thus, it is seen that at the corrosion damage edge over cross section (path 3) the $\sigma_{t}$ distribution has an essentially peculiar pattern. The $\sigma_{t}$ variations in the calculation for (1), (8) along paths 1, 2, 3 are identical to those in the calculation for (1) and are approximately 3, 1.5 and $15 \%$, respectively. However unlike the calculation for (1), in the calculation for (1), (8) $\sigma_{t}$ increases a little (up to $1 \%$ ) along path 4 .

The stress $\sigma_{r}$ distributions shown in Figures 23 and 24 illustrate a qualitative agreement of the results of the analytical and finite-element calculations for (1). In the calculation for (1) $\left|\sigma_{r}\right|$ is approximately by $70 \%$ higher at the damage edge than the one at the inner surface without damage.

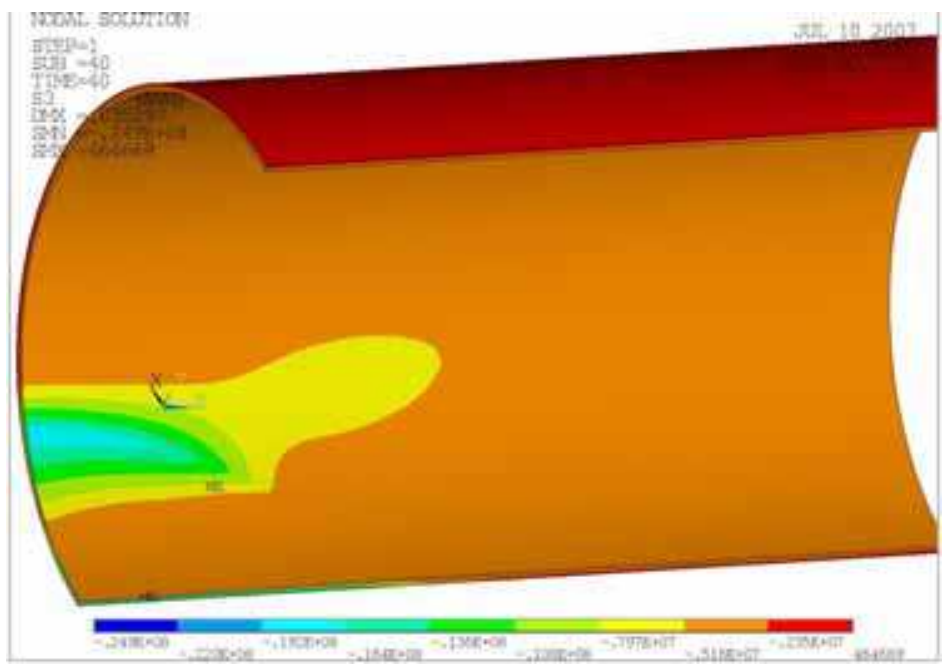

Fig. 23. Distribution of the stress $\sigma_{3}\left(\sigma_{r}\right)$ at $\left.\sigma_{r}\right|_{r=r_{1}}=p$

In the calculation for (1), (8), because of the soil pressure, $\left|\sigma_{r}\right|$ practically does not vary in the damage vicinity.

Maximum and minimum values of $\sigma_{r}$ in the calculation for (1) are: $\sigma_{r}^{\min }=-2.49 \cdot 10^{7} \mathrm{~Pa}$ and $\sigma_{r}^{\max }=4.64 \cdot 10^{5} \mathrm{~Pa}$; in the calculation for (1), (8): $\sigma_{r}^{\min }=-1.62 \cdot 10^{7} \mathrm{~Pa}$ and $\sigma_{r}^{\max }=1.09 \cdot 10^{6}$ Pa.

Figures 1.18-1.28 plot the distributions of the principal stresses corresponding to the sresses $\sigma_{t}, \sigma_{r}, \sigma_{z}$ for different fixing types. From the comparison of theses distributions it is seen that four forms of boundary conditions form two qualitatively different types of the stress $\sigma_{t}$ distributions. So, in the case of rigid fixing of the outer surface of the pipe (at $\left.u_{x}\right|_{r=r_{2}}=\left.u_{y}\right|_{r=r_{2}}=0$ or $\left.\left.u_{x}\right|_{r=r_{2}}=\left.u_{y}\right|_{r=r_{2}}=\left.u_{z}\right|_{r=r_{2}}=0\right) \sigma_{t}<0$. In the case, fixing is absent and contact is present, $\sigma_{t}>0$. At the contact interaction between the pipe and soil, the level due to the pressure soil in $\sigma_{t}$ is approximately three times less than in the absence of fixing. The 


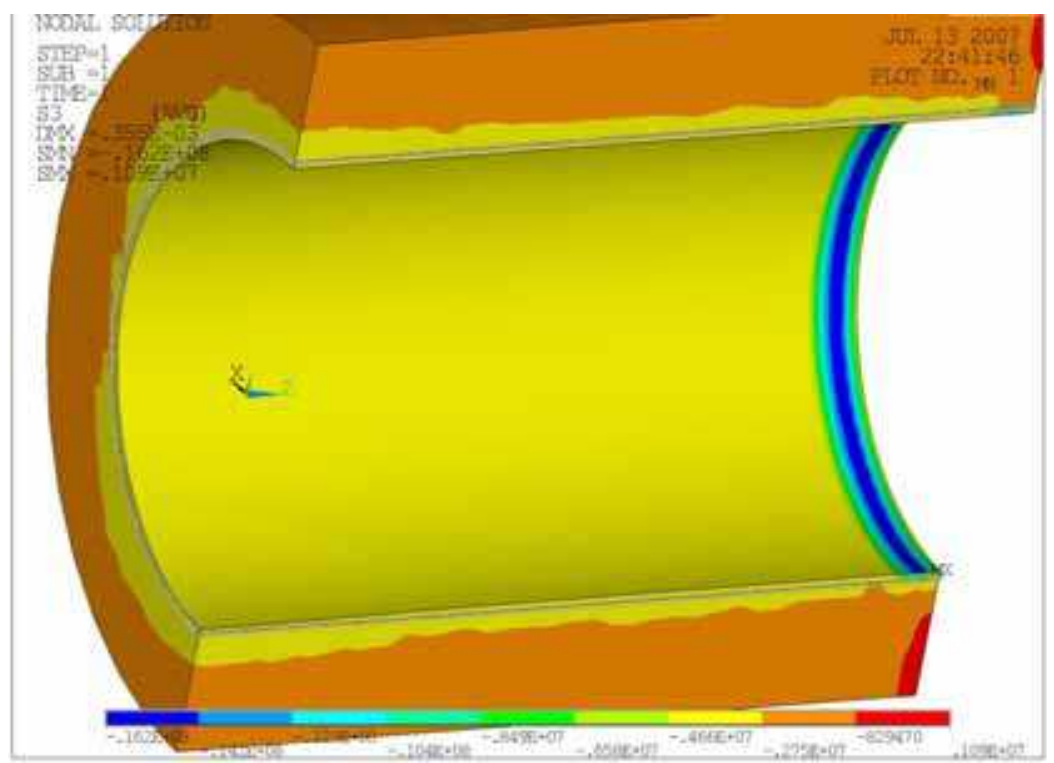

Fig. 24. Distribution of the stress $\sigma_{3}\left(\sigma_{r}\right)$ at $\left.\sigma_{r}\right|_{r=r_{1}}=p,\left.\sigma_{r}^{(1)}\right|_{r=r_{2}}=-\left.\sigma_{r}^{(2)}\right|_{r=r_{2}}$, $\left.\sigma_{\tau}^{(1)}\right|_{r=r_{2}}=-\left.\sigma_{\tau}^{(2)}\right|_{r=r_{2}}=\left.f \sigma_{n}^{(1)}\right|_{r=r_{2}},\left.u_{x}\right|_{r=r_{3}}=\left.u_{y}\right|_{r=r_{3}}=0$

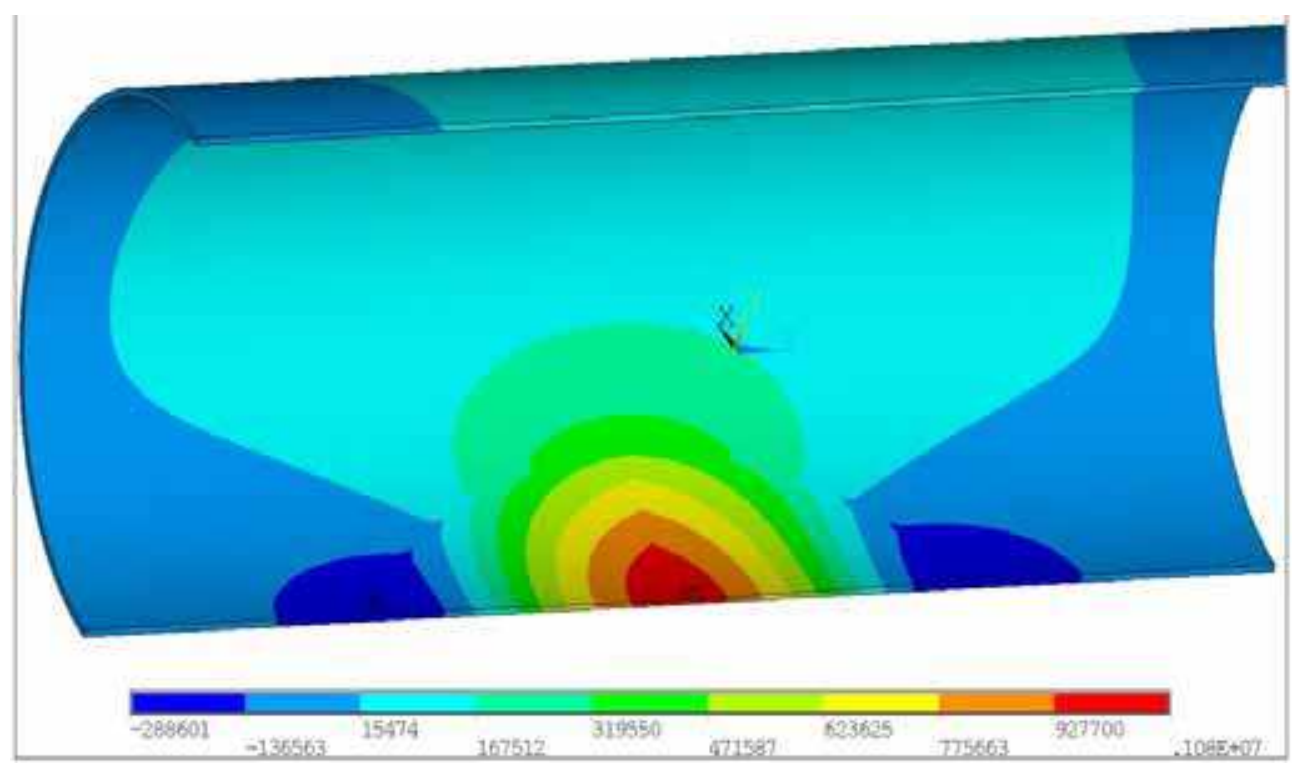

Fig. 25. Distribution of the stress $\sigma_{z}$ at $\left.\sigma_{r}\right|_{r=r_{1}}=p,\left.u_{x}\right|_{r=r_{2}}=\left.u_{y}\right|_{r=r_{2}}=0$ 


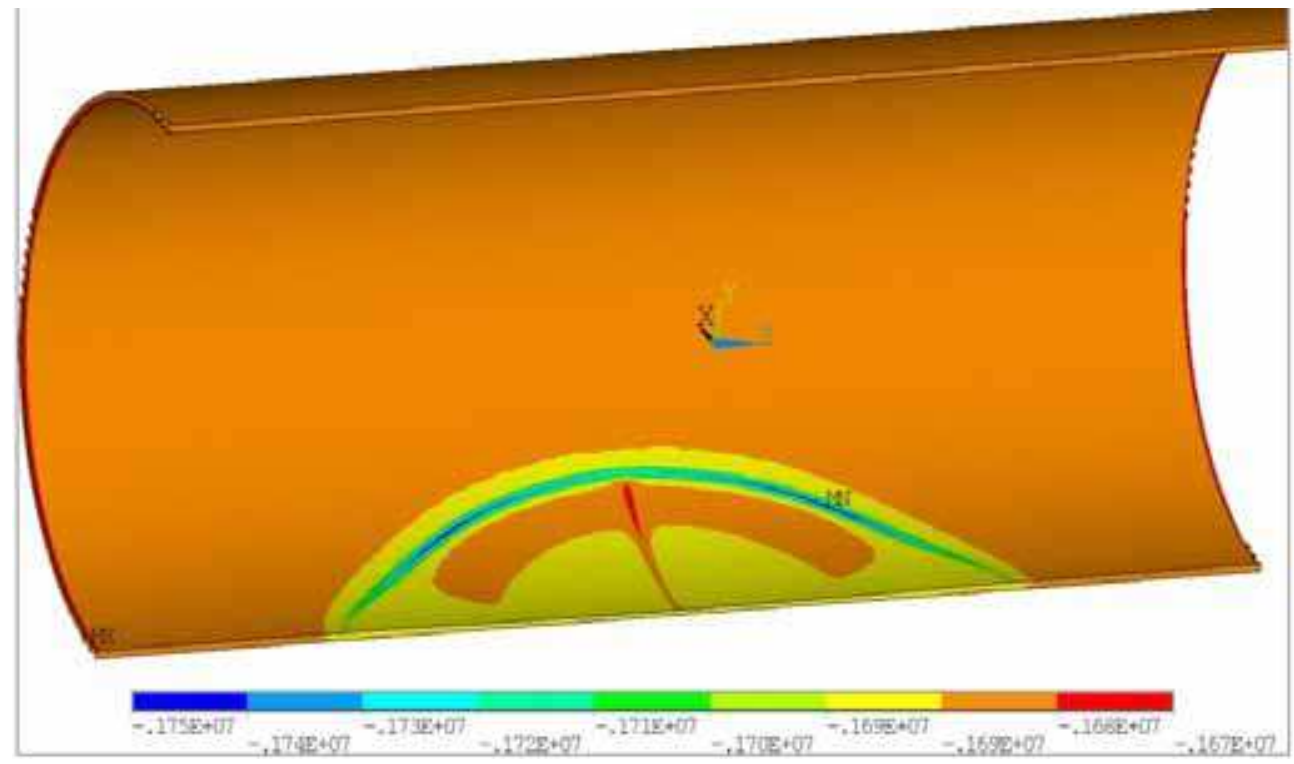

Fig. 26. Distribution of the stress $\sigma_{z}$ at $\left.\sigma_{r}\right|_{r=r_{1}}=p,\left.u_{x}\right|_{r=r_{2}}=\left.u_{y}\right|_{r=r_{2}}=\left.u_{z}\right|_{r=r_{2}}=0$

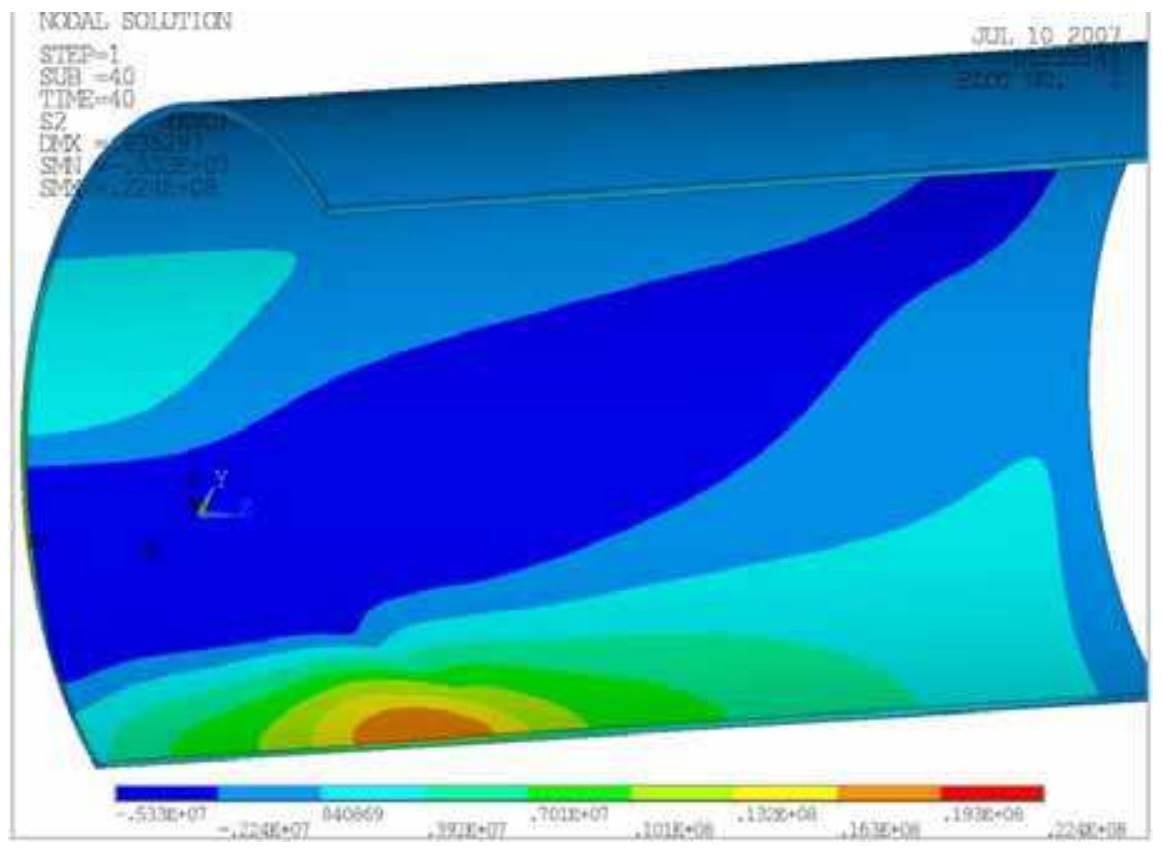

Fig. 27. Distirbution of the stress $\sigma_{2}\left(\sigma_{z}\right)$ at $\left.\sigma_{r}\right|_{r=r_{1}}=p$ 
$\sigma_{t}<0$ distributions over the inner surface of the pipe are qualitatively and quantitatively indentical in all calculations. The $\sigma_{z}$ distributions are essensially different for the considered calculations. In the calculations for $\left.u_{x}\right|_{r=r_{2}}=\left.u_{y}\right|_{r=r_{2}}=0$ and in the absence of fixing, there exist regions of both tensile and compressive stresses $\sigma_{z}$. In the calculation for $\left.u_{x}\right|_{r=r_{2}}=\left.u_{y}\right|_{r=r_{2}}=\left.u_{z}\right|_{r=r_{2}}=0$, the peculiarities of the $\sigma_{z}<0$ distributions manefest themselves just in the damage region (fixing influence in all directions). At the contact interaction between the pipe and soil, the $\sigma_{z}>0$ distribution in the damage region is similar to the distribution for $\left.u_{x}\right|_{r=r_{2}}=\left.u_{y}\right|_{r=r_{2}}=0$.

The bulk analysis of the stress distributions has shown that the results of calculation of the contact interaction of the pipe and soil are intermediate between the calculation results for the extreme cases of fixing. So, the $\sigma_{r}<0$ distribution has a similar pattern in all calculations. By the $\sigma_{t}$ distribution, the case of the contact between the pipe and soil is close to that of absent fixing since in these calculations the boundary conditions allow the pipe to be expanded in the radial direction. By the $\sigma_{z}$ distributions, the case of the contact between the pipe and soil is close for $\left.u_{x}\right|_{r=r_{2}}=\left.u_{y}\right|_{r=r_{2}}=0$, since in these calculations for the outer surface of the pipe, displacements along the $z$ axis of the pipe are possible and at the same time displacements in the radial direction are limited.

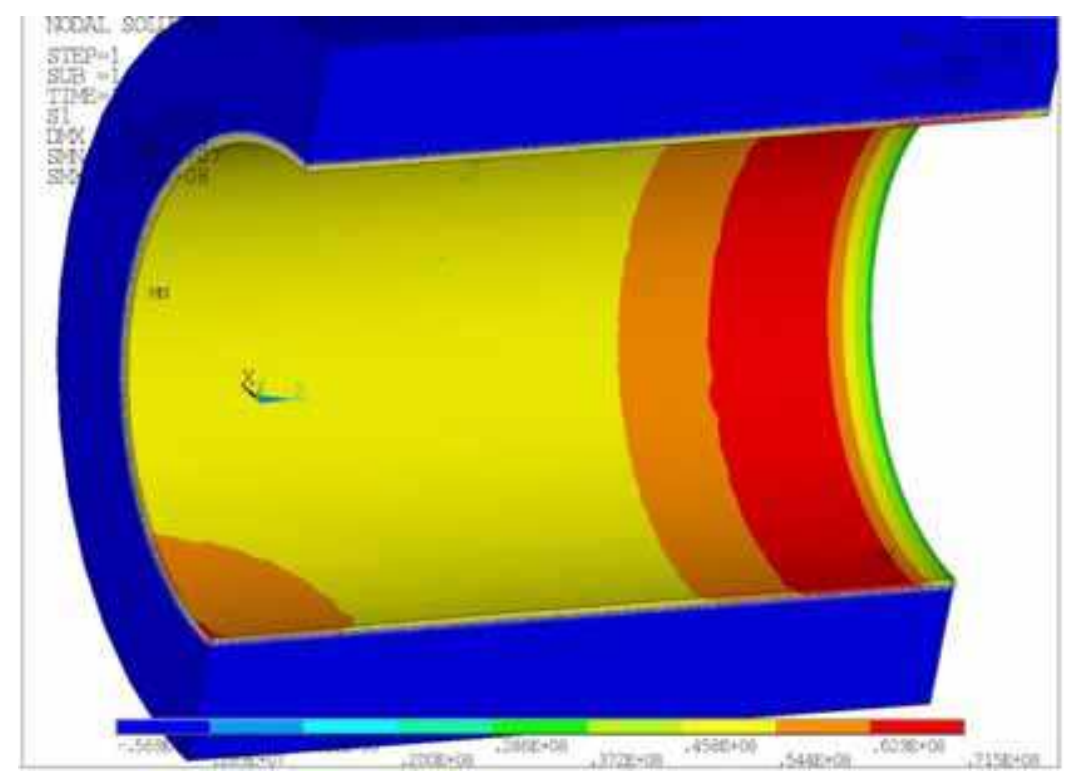

Fig. 28. Distribution of the stress $\sigma_{1}\left(\sigma_{z}\right)$ at $\left.\sigma_{r}\right|_{r=r_{1}}=p,\left.\sigma_{r}^{(1)}\right|_{r=r_{2}}=-\left.\sigma_{r}^{(2)}\right|_{r=r_{2}}$,

$\left.\sigma_{\tau}^{(1)}\right|_{r=r_{2}}=-\left.\sigma_{\tau}^{(2)}\right|_{r=r_{2}}=\left.f \sigma_{n}^{(1)}\right|_{r=r_{2}},\left.u_{x}\right|_{r=r_{3}}=\left.u_{y}\right|_{r=r_{3}}=0$ 
The corrosion damage disturbance of the strain state of the pipe as a whole corresponds to the disturbance of the stress state (Figures 29-34). The exception is only $\varepsilon_{t}$ (Figures 29, 30) that is tensile at the entire inner surface of the pipe, except for the damage edge where it becomes essentially compressive. This effect in principle corresponds to the effect of developing compressive strains inside the damage in a total compressive strain field. This effect was reaveled during full-scale pressure tests of pipes.

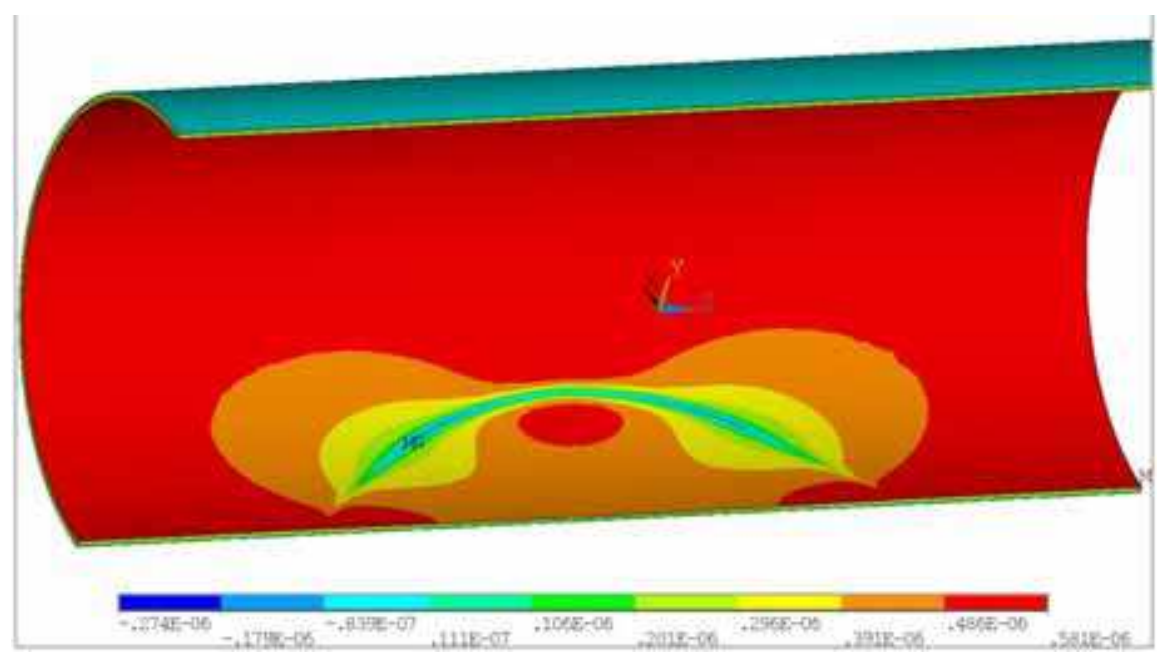

Fig. 29. Strains $\varepsilon_{t}$ at $\left.\sigma_{r}\right|_{r=r_{1}}=p,\left.u_{x}\right|_{r=r_{2}}=\left.u_{y}\right|_{r=r_{2}}=0$

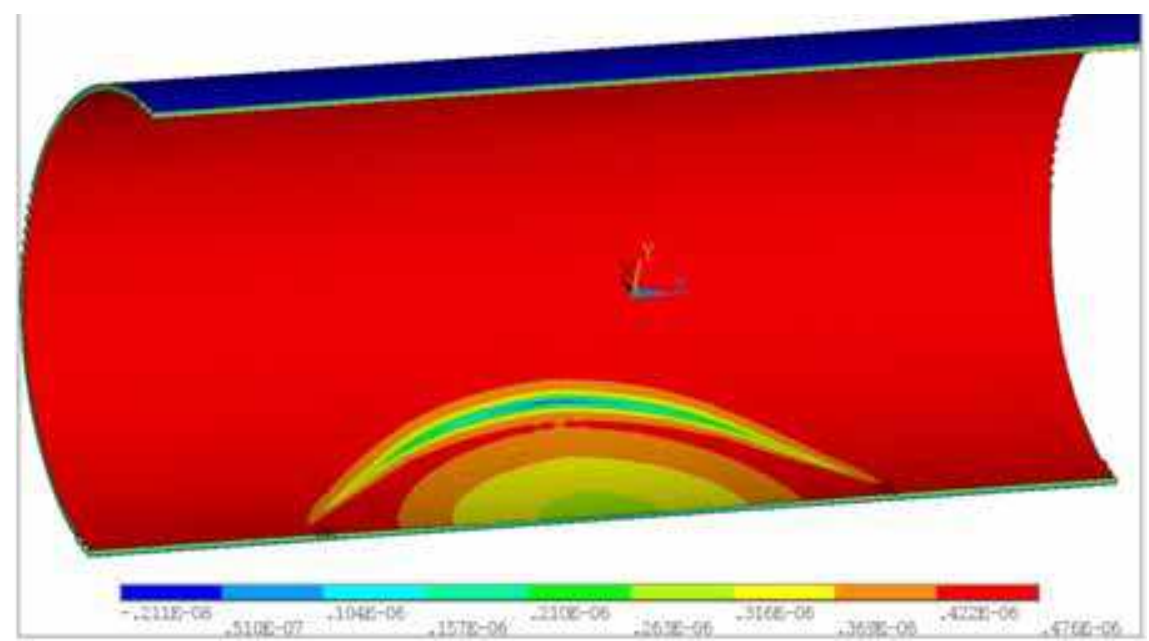

Fig. 30. Strains $\varepsilon_{t}$ at $\left.\sigma_{r}\right|_{r=r_{1}}=p,\left.u_{x}\right|_{r=r_{2}}=\left.u_{y}\right|_{r=r_{2}}=\left.u_{z}\right|_{r=r_{2}}=0$ 
Three-Dimensional Stress-Strain State of a Pipe with Corrosion Damage Under Complex Loading 165

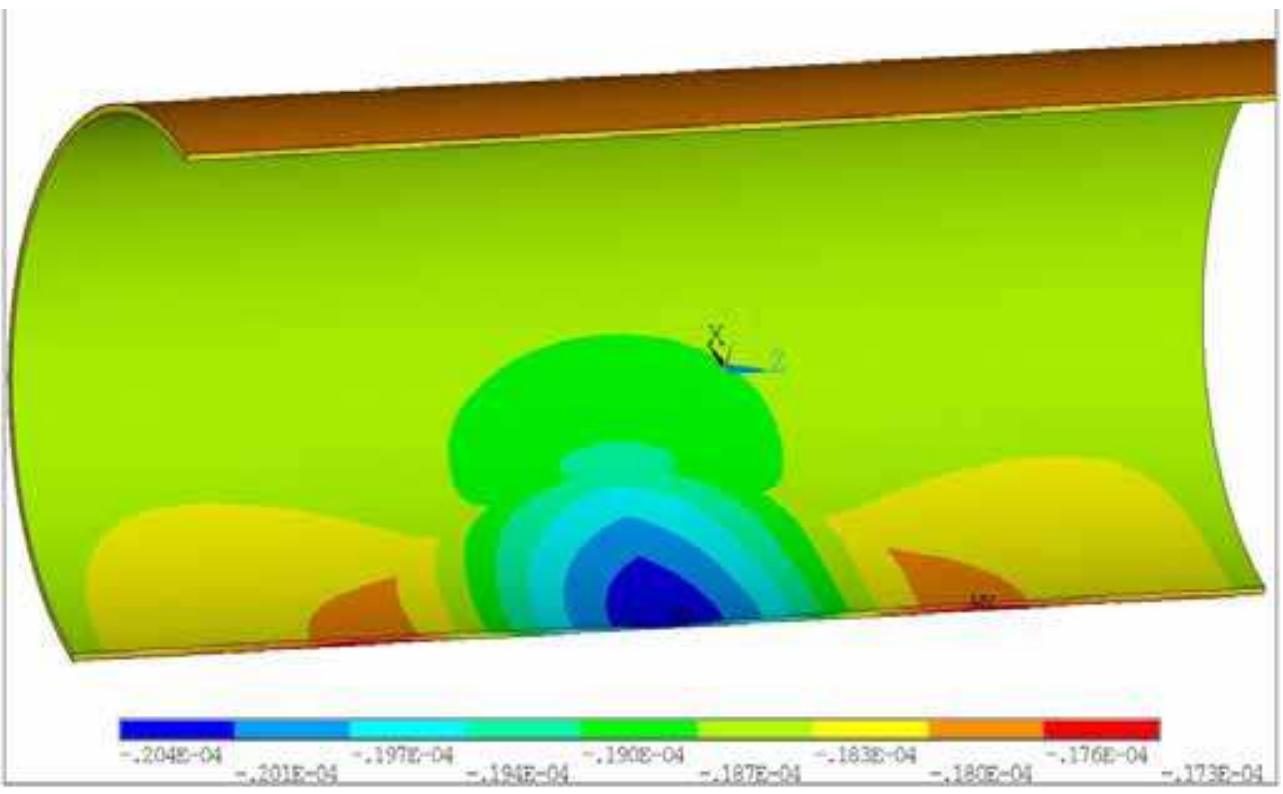

Fig. 31. Strains $\varepsilon_{r}$ at $\left.\sigma_{r}\right|_{r=r_{1}}=p,\left.u_{x}\right|_{r=r_{2}}=\left.u_{y}\right|_{r=r_{2}}=0$

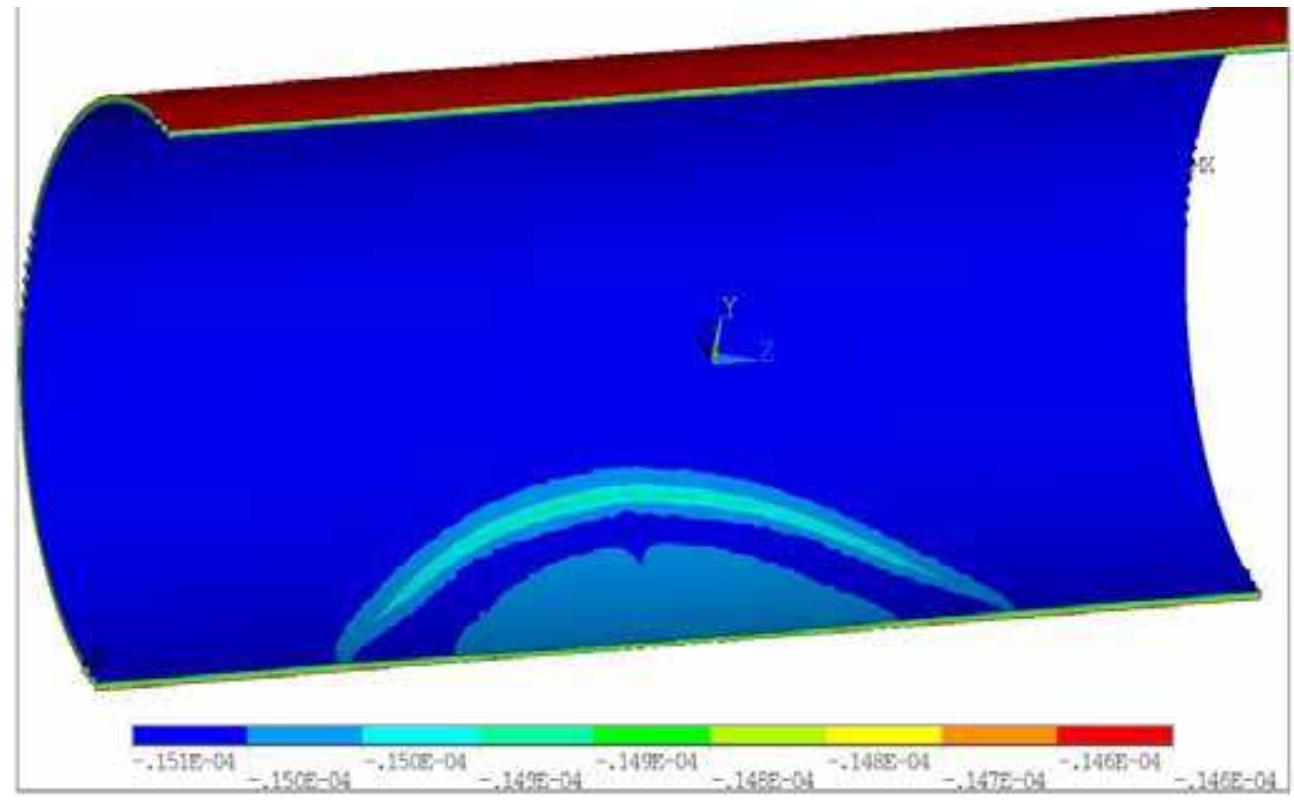

Fig. 32. Strains $\varepsilon_{r}$ at $\left.\sigma_{r}\right|_{r=r_{1}}=p,\left.u_{x}\right|_{r=r_{2}}=\left.u_{y}\right|_{r=r_{2}}=\left.u_{z}\right|_{r=r_{2}}=0$ 


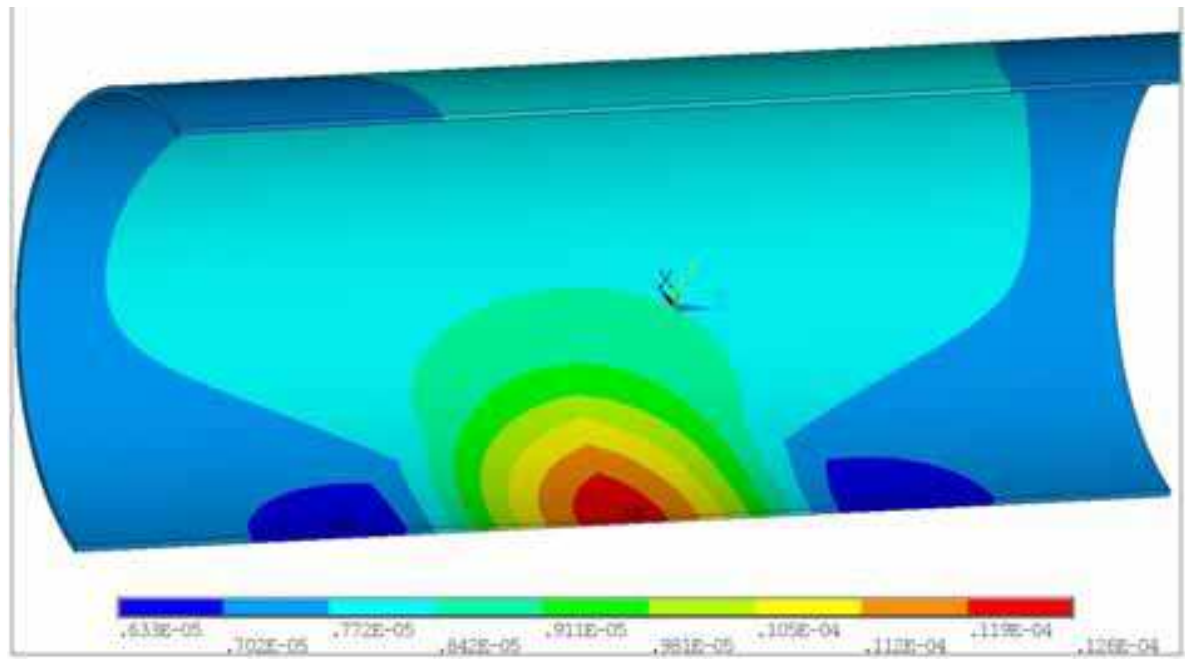

Fig. 33. Strains $\varepsilon_{z}$ at $\left.\sigma_{r}\right|_{r=r_{1}}=p,\left.u_{x}\right|_{r=r_{2}}=\left.u_{y}\right|_{r=r_{2}}=0$

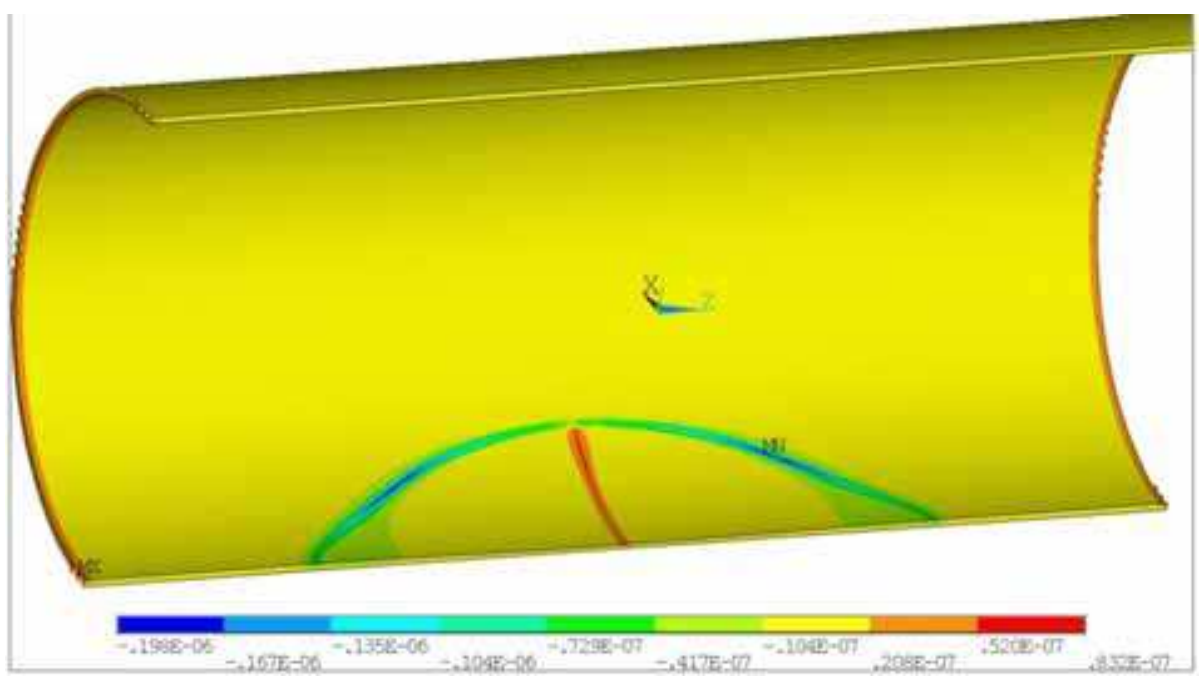

Fig. 34. Strains $\varepsilon_{z}$ at $\left.\sigma_{r}\right|_{r=r_{1}}=p,\left.u_{x}\right|_{r=r_{2}}=\left.u_{y}\right|_{r=r_{2}}=\left.u_{z}\right|_{r=r_{2}}=0$

\section{Influnce of different loading types on the stress-strain state of three- dimensional pipe models}

Figures 35, 36 present the distributions of the principal stresses corresponding to the stresses $\sigma_{t}$ for different loading types in the absence of fixing of the outer surface of the pipe. From the comparison of these distributions it is seen that three loading types form three 
characteristic distribution types of the stresses $\sigma_{i j}^{(p)}, \sigma_{i j}^{(T)}, \sigma_{i j}^{(p+T)}$ such that according to (10) $\sigma_{i j}^{(p+T)}=\sigma_{i j}^{(p)}+\sigma_{i j}^{(T)}$.

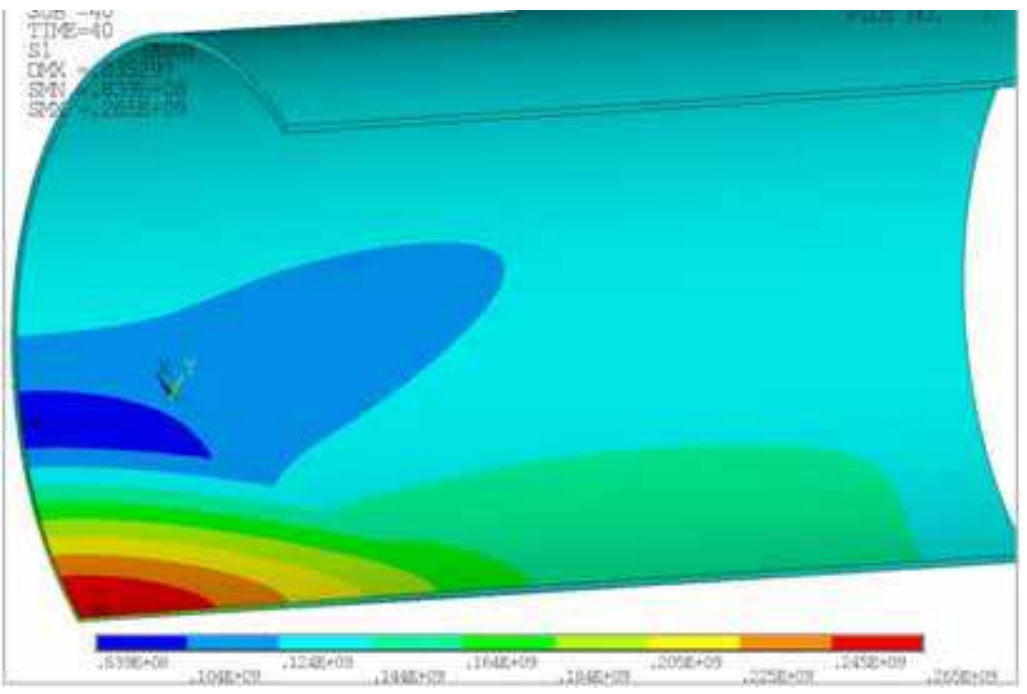

Fig. 35. Distribution of the stress $\sigma_{1}\left(\sigma_{t}\right)$ in the absence of the outer surface fixing for $\left.\sigma_{r}\right|_{r=r_{1}}=p$

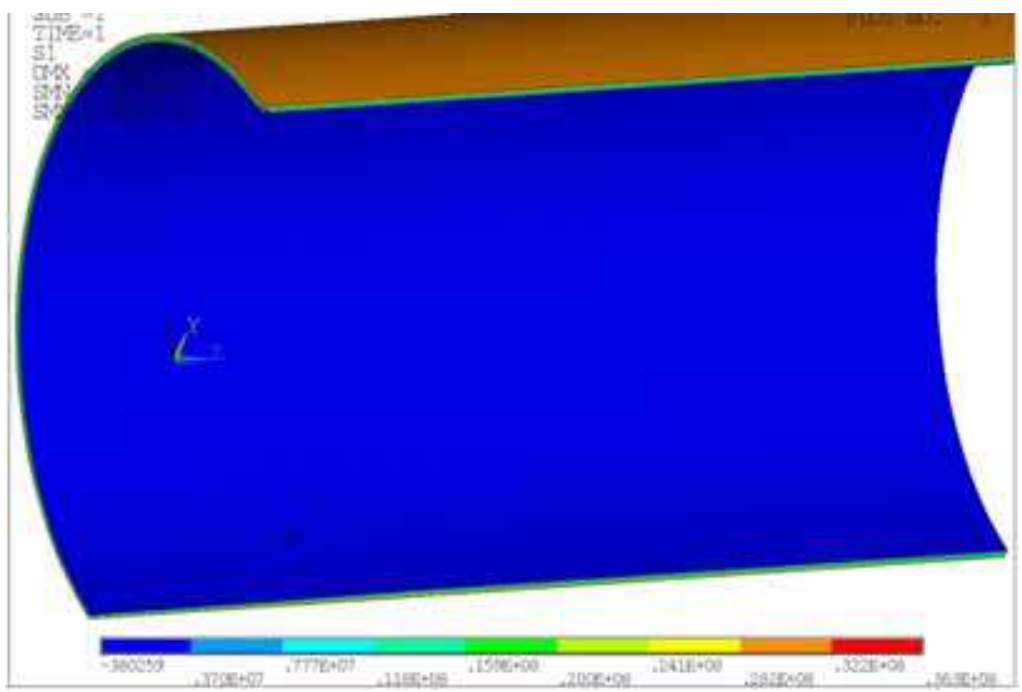

Fig. 36. Distribution of the stress $\sigma_{1}\left(\sigma_{t}\right)$ in the absence of the outer surface fixing for $\left|T_{r_{1}}-T_{r_{2}}\right|=\Delta T$ 
A comparative analysis of the stress distributions along the assigned paths shows that at the corrosion damage center (path 2) there is an almost two-fold increase of the stresses $\left(\sigma_{t}\right)$, as compared to the surface of the pipe without damage (path 1). The disturbing effect of corrosion damage (path 6) on the stress state is clearly seen.

Figures 37-39 plot the distributions of the principal stresses corresponding to the stresses $\sigma_{t}$ for different loading types when displacements are absent along the $x$ and $y$ axes of the outer surface of the pipe $\left.u_{x}\right|_{r=r_{2}}=\left.u_{y}\right|_{r=r_{2}}=0$ and along the $z$ axis at the right end $\left.u_{z}\right|_{z=L}=0$ when friction is present at the inner surface $\left.\tau_{r z}\right|_{r=r_{1}} \neq 0$. From the comparison of these figures it is possible to single out several characteristic distribution types of the stresses $\sigma_{i j}^{(p)}, \sigma_{i j}^{(\tau)}, \sigma_{i j}^{(T)}, \sigma_{i j}^{(p+\tau)}, \sigma_{i j}^{(p+T)}, \sigma_{i j}^{(p+\tau+T)}$ related by (10).

Figures 1.37-1.38 illustrate a noticeable influence of the viscous fluid (oil) pipe wall friction $\left(\sigma_{i j}^{(\tau)}\right)$ on the $\sigma_{i j}^{(p+\tau)}$ formation. From Figure 39 it is seen that temeprature stresses are dominant, exceeding by no less than 2-3 times the stresses developed by the action of $\left.\sigma_{r}\right|_{r=r_{1}}=p=4 \mathrm{MPa},\left.\tau_{r z}\right|_{r=r_{1}}=\tau_{0}=260 \mathrm{~Pa}$. In view of the fact that the temperature difference $\left|T_{r_{1}}-T_{r_{2}}\right|=\Delta T=20^{\circ} \mathrm{C}$ exerts a dramatic influence on the formation of the stress state of the pipe, the distributions of $\sigma_{i j}^{(p+T)}$ and $\sigma_{i j}^{(p+\tau+T)}$ are qualitatively similar to the $\sigma_{i j}^{(p+\tau+T)}$ distribution, slightly differing in numerical values.

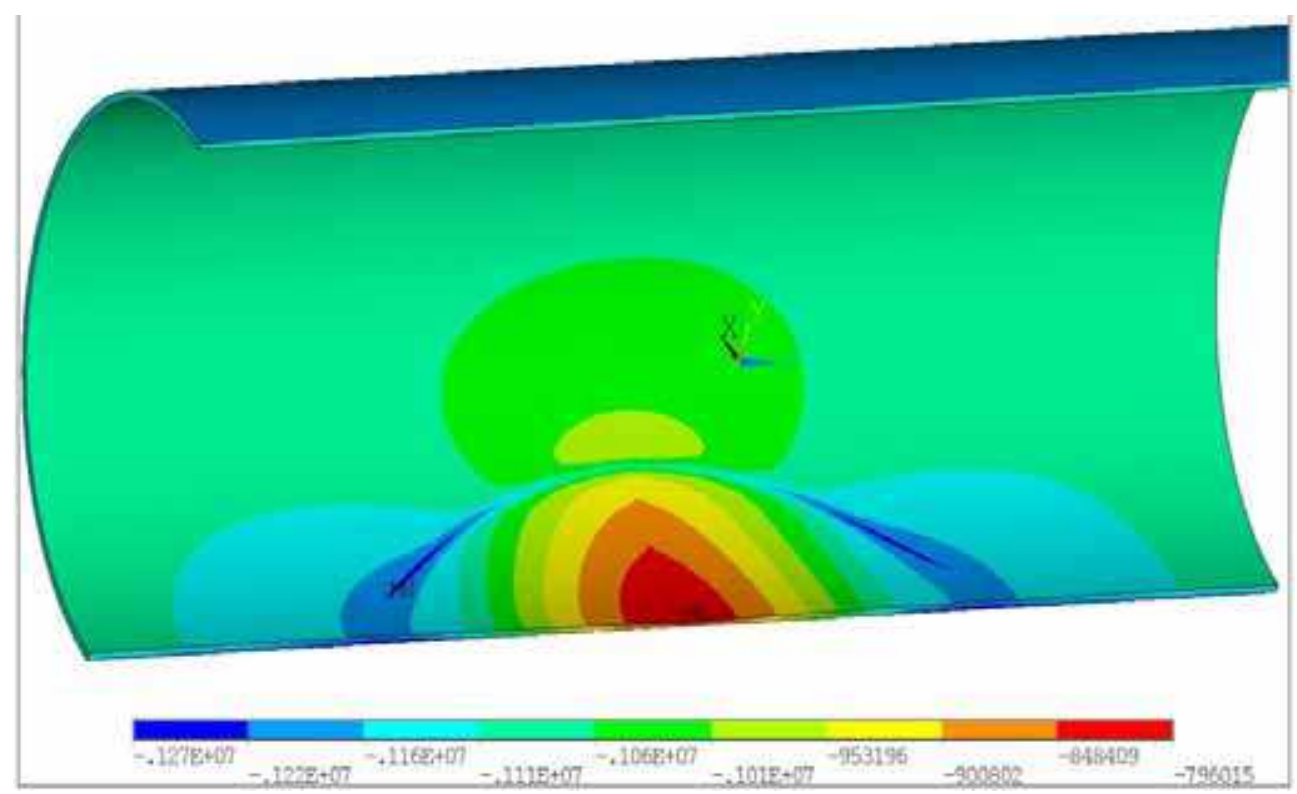

Fig. 37. Distribition pf the stress $\sigma_{1}\left(\sigma_{i j}^{(p)}\right)$ at $\left.u_{x}\right|_{r=r_{2}}=\left.u_{y}\right|_{r=r_{2}}=0$ for $\left.\sigma_{r}\right|_{r=r_{1}}=p$ 


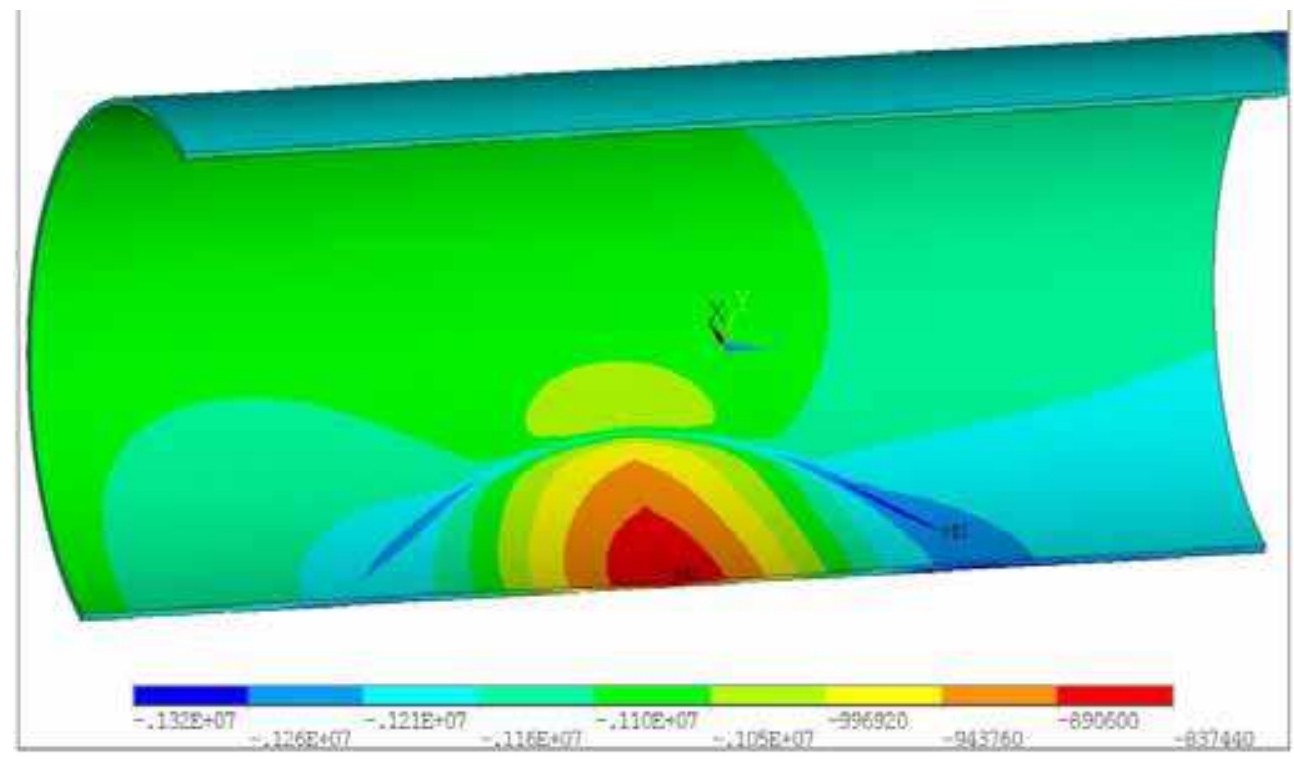

Fig. 38. Distribution of the stress $\sigma_{1}\left(\sigma_{i j}^{(p+\tau)}\right)$ at $\left.u_{x}\right|_{r=r_{2}}=\left.u_{y}\right|_{r=r_{2}}=0,\left.u_{z}\right|_{z=L}=0$ for $\left.\sigma_{r}\right|_{r=r_{1}}=p$, $\left.\tau_{r z}\right|_{r=r_{1}}=\tau_{0}$

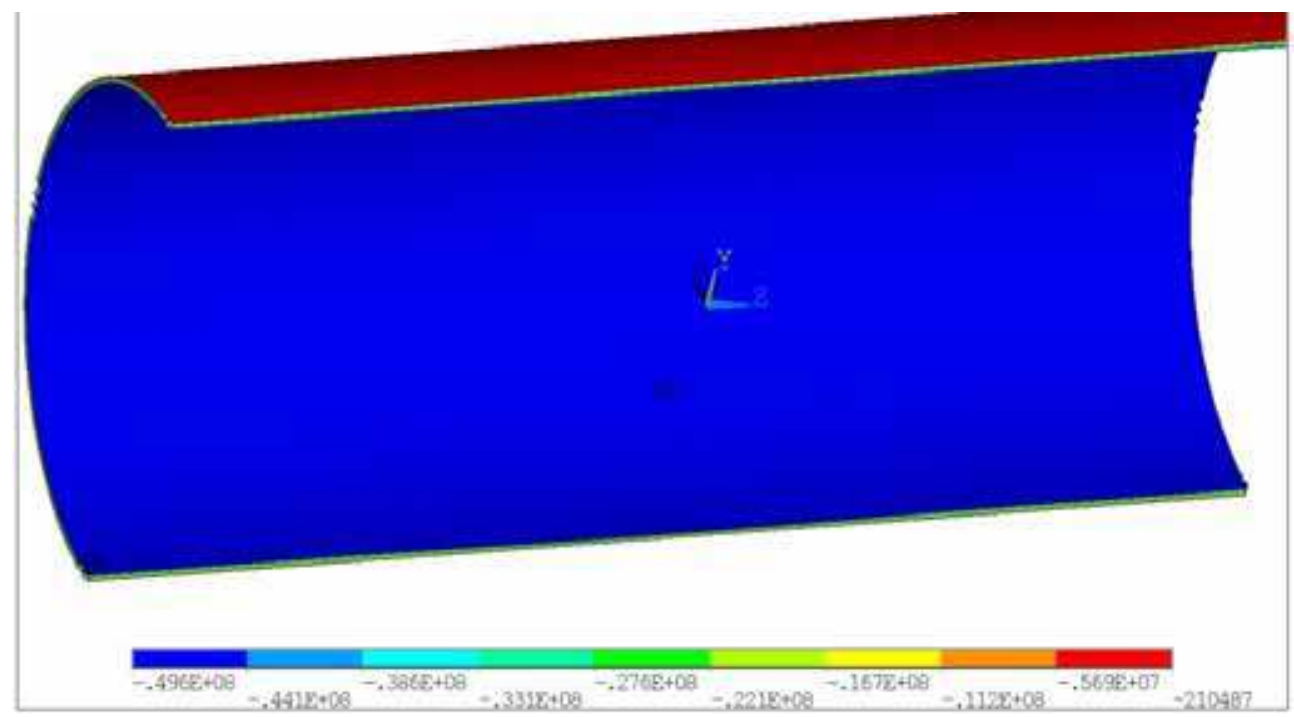

Fig. 39. Distribution of the stress $\sigma_{1}\left(\sigma_{i j}^{(p+\tau+T)}\right)$ at $\left.u_{x}\right|_{r=r_{2}}=\left.u_{y}\right|_{r=r_{2}}=0,\left.u_{z}\right|_{z=L}=0$ for $\left.\sigma_{r}\right|_{r=r_{1}}=p,\left.\tau_{r z}\right|_{r=r_{1}}=\tau_{0},\left|T_{r_{1}}-T_{r_{2}}\right|=\Delta T$ 
A comparative analysis of the stress distributions shows that at the corrosion damage center the stresses grow (almost two-fold increase for $\sigma_{t}$ ) in comparison with the surface of the pipe without damage.

\section{Conclusion}

Within the framework of the investigations made, the method for evaluation of the influence of the process of friction of moving oil on the damage of the inner surface of the pipe has been developed. The method involves analytical and numerical calculations of the motion of the two-and three-dimensional flow of viscous fluid (oil) in the pipe within laminar and turbulent regimes, with different average flow velocities at some internal pipe pressure, in the presence or the absence of corrosion damage at the inner surface of the pipe.

The method allows defining a broad spectrum of flow motion characteristics, including: velocity, energy and turbulence intensity, a value of tangential stresses (friction force) caused by the flow motion at the inner surface of the pipe.

The method for evaluation of the stress-strain state of two-and three-dimensional pipe models as acted upon by internal pressure, uniformly distributed tangential stresses over the inner surface of the pipe (pipe flow friction forces), and temperature with regard to corrosion-erosion damages of the inner surface of the pipe has been developed, too. For finite-element pipe models with boundary conditions of type (1)-(7) mainly the circumferential stresses, being the largest, were considered.

The methof allows defining the variation in the values of the tensor components of stresses and strains in the pipe with corrosion damage for assigned pipe fixing under individual loading (temperature, pressure, fluid flow friction over the inner surface of the pipe) and their different combinations.

\section{References}

[1] Ainbinder A.B., Kamershtein A.G. Strength and stability calculation of trunk pipelines. M: Nedra, 1982. - 344 p.

[2] Borodavkin P.P., Sinyukov A.M. Strength of trunk pipelines. M: Nedra, 1984. - 286 p.

[3] Grachev V.V., Guseinzade M.A., Yakovlev E.I. et al. Complex pipeline systems. M: Nedra, 1982. -410 p.

[4] Handbook on the designing of trunk pipelines / Ed, by A.K. Dertsakyan. L: Nedra, 1977. $-519 \mathrm{p}$.

[5] Kostyuchenko A.A. Influence of friction due to the oil flow on the pipe loading / A.A. Kostyuchenko, S.S. Sherbakov, N.A. Zalessky, P.A. Ivankin, L.A. Sosnovskiy // Reliability and safety of the trunk pipeline transportation: Proc. VI International Scientific-Technical Conference, Novopolotsk, 11-14 December 2007 / PSU; eds: V.K. Lipsky et al. - Novopolotsk, 2007 a. - P. 76-78.

[6] Kostyuchenko A.A. Wall friction in the turbulent oil flow motion in the pipe with corrosion defect / A.A. Kostyuchenko, S.S. Sherbakov, N.A. Zalessky, P.S. Ivankin, L.A. Sosnovskiy // Reliability and safety of the trunk pipeline transportation: Proc. VI International Scientific-Technical Conference, 
Novopolotsk, 11-14 December 2007 / PSU; eds: V.K. Lipsky et al. -Novopolotsk, 2007 b. - P. 78-80.

[7] Launder B.E., Spalding D.B. Mathematical Models of Turbulence. London: Academic Press, 1972.

[8] Mirkin A.Z., Usinysh V.V. Pipeline systems: Handbook Edition. M: Khimiya, 1991. - 286 p.

[9] O'Grady T.J., Hisey D.T., Kiefner J. F. Pressure calculation for corroded pipe developed // Oil \& Gas J. 1992. Vol. 42. - P. 64-68.

[10] Ponomarev S.D. Strength calculations in engineering industry / S.D. Ponomarev, V.D. Biderman, K.K. Likharev, V.M. Makushin, N.N. Malinin, V.I. Fedosiev. M: State Scientific-Technical Publishing House of Engineering Literature, 1958. Vol. 2. $-974 \mathrm{p}$.

[11] Rodi W. A new algebraic relation for calculating the Reynolds stresses //ZAMM 56. 1976.

[12] Sedov L.I. Continuum mechanics: in 2 volumes. $6^{\text {th }}$ edition, Saint-Petersburg: Lan', 2004. 2nd vol.

[13] Seleznev V.E., Aleshin V.V., Pryalov S.N. Fundamentals of numerical modeling of trunk pipelines / Ed. by V.E. Seleznev. - M: KomKniga, 2005. - 496 p.

[14] Sherbakov S.S. Influence of fixing of a pipe with a corrosion defect on its stress-strain state / S.S. Sherbakov, N.A. Zalessky, P.A. Ivankin, V.V. Vorobiev // Reliability and safety of the trunk pipeline transportation: Proc. VI International ScientificTechnical Conference, Novopolotsk, 11-14 December 2007 / PSU; eds: V.K. Lipsky et al. - Novopolotsk, 2007 a. - P. 52-55.

[15] Sherbakov S.S. Modeling of the three-dimensional stress-strain state of a pipe with a corrosion defect under complex loading / S.S. Sherbakov, N.A. Zalessky, P.S. Ivankin, L.A. Sosnovskiy// Reliability and safety of the trunk pipeline transportation: Proc. VI International Scientific-Technical Conference, Novopolotsk, 11-14 December 2007 / PSU; eds: V.K. Lipsky et al. - Novopolotsk, 2007 b. - P. 55-58.

[16] Sherbakov S.S. Modeling of the stress-strain state of a pipe with a corrosion defect under complex loading / S.S. Shcherbakov, N.A. Zalessky, P.S. Ivankin // $X$ Belarusian Mathematical Conference: Abstract of the paper submitted to the International Scientific Conference, Minsk, 3-7 Novermber 2008 - Part 4. Minsk: Press of the Institute of Mathematics of NAS of Belarus, 2008. - P. 5354.

[17] Sherbakov S.S. Influence of wall friction in the turbulent oil flow motion in the pipe with a corrosion defect on the stress-strain state of the pipe / S.S. Sherbakov // Strength and reliability of trunk pipelines (Abstracts of the papers submitted to the International Scientific-Technical Conference "MT-2008", Kiev, 5-7 June 2008). Kiev: IPS NAS Ukraine, 2008. - P.120-121.

[18] Sosnovskiy L.A. Modeling of the stress-strain state of pipes of trunk pipelines with corrosion defects with regard to pressure, temperature, and interaction between the oil flow and the inner surface / L.A. Sosnovskiy, S.S. Sherbakov // Strength and safety of trunk pipelines (Abstracts of the papers submitted to the International 
Scientific-Technical Conference "MT-2008”, Kiev, 5-7 June 2008). - Kiev: IPS NAS Ukraine 2008. - Pp. 107-108. 


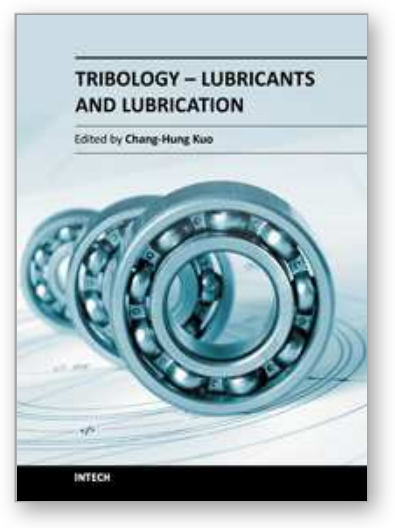

\author{
Tribology - Lubricants and Lubrication \\ Edited by Dr. Chang-Hung Kuo
}

ISBN 978-953-307-371-2

Hard cover, 320 pages

Publisher InTech

Published online 12, October, 2011

Published in print edition October, 2011

In the past decades, significant advances in tribology have been made as engineers strive to develop more reliable and high performance products. The advancements are mainly driven by the evolution of computational techniques and experimental characterization that leads to a thorough understanding of tribological process on both macro- and microscales. The purpose of this book is to present recent progress of researchers on the hydrodynamic lubrication analysis and the lubrication tests for biodegradable lubricants.

\title{
How to reference
}

In order to correctly reference this scholarly work, feel free to copy and paste the following:

S. Sherbakov (2011). Three-Dimensional Stress-Strain State of a Pipe with Corrosion Damage Under Complex Loading, Tribology - Lubricants and Lubrication, Dr. Chang-Hung Kuo (Ed.), ISBN: 978-953-307-371-2, InTech, Available from: http://www.intechopen.com/books/tribology-lubricants-and-lubrication/threedimensional-stress-strain-state-of-a-pipe-with-corrosion-damage-under-complex-loading

\section{INTECH}

open science | open minds

\author{
InTech Europe \\ University Campus STeP Ri \\ Slavka Krautzeka 83/A \\ 51000 Rijeka, Croatia \\ Phone: +385 (51) 770447 \\ Fax: +385 (51) 686166 \\ www.intechopen.com
}

\author{
InTech China \\ Unit 405, Office Block, Hotel Equatorial Shanghai \\ No.65, Yan An Road (West), Shanghai, 200040, China \\ 中国上海市延安西路65号上海国际贵都大饭店办公楼 405 单元 \\ Phone: +86-21-62489820 \\ Fax: $+86-21-62489821$
}


(C) 2011 The Author(s). Licensee IntechOpen. This is an open access article distributed under the terms of the Creative Commons Attribution 3.0 License, which permits unrestricted use, distribution, and reproduction in any medium, provided the original work is properly cited. 